\title{
Research, Development, and Demonstration of Algal Production Raceway (APR) Systems for the Production of Hydrocarbon Resources
}

\section{A Subcontract Report}

Edward A. Laws

University of Hawaii, Oceanography Department, and Hawaii Institute of Marine Biology

Honolulu, Hawaii

February 1984

Prepared under Subcontract No. XE-0-9013-01

SERI Technical Monitor: Robins McIntosh

Solar Energy Research Institute

A Division of Midwest Research Institute

1617 Cole Boulevard

Golden, Colorado 80401

Prepared for the

U.S. Department of Energy

Contract No. DE-AC02-83CH10093 
Printed in the United States of America Available from:

National Technical Information Service

U.S. Department of Commerce

5285 Port Royal Road

Springfield, VA 22161

Price:

Microfiche A01

Printed Copy A04

\begin{abstract}
NOTICE
This report was prepared as an account of work sponsored by the United States Government. Neither the United States nor the United States Department of Energy, nor any of their employees, nor any of their contractors, subcontractors, or their employees, makes any warranty, express or implied, or assumes any legal liability or responsibility for the accuracy, completeness or usefulness of any information, apparatus, product or process disclosed, or represents that its use would not infringe privately owned rights.
\end{abstract}




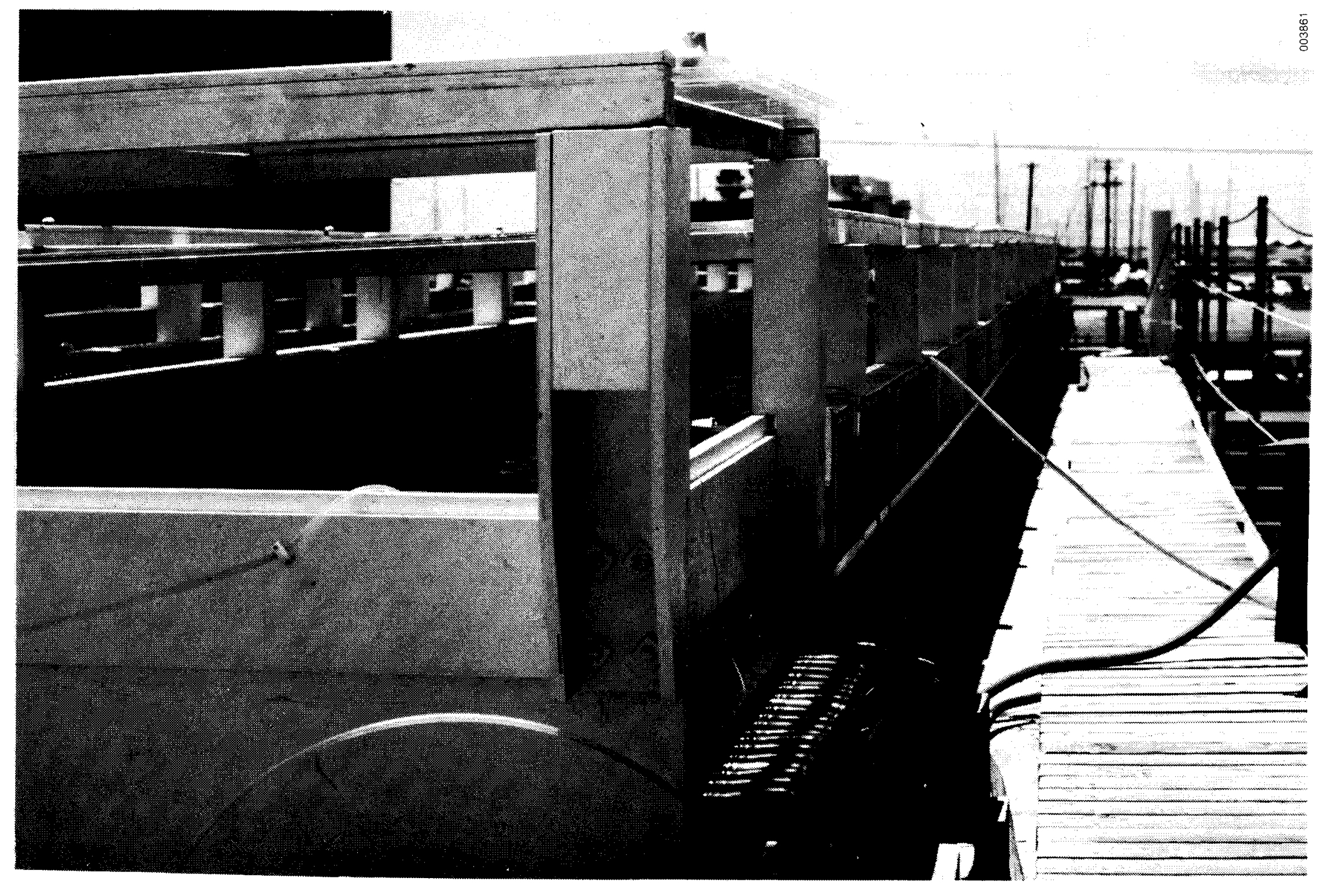




\section{FOREWORD}

This report is the final report for FY 1983. The work was performed under subcontract to SERI with funds provided by the Biomass Energy Technology Division of the U.S. Department of Energy, under a program investigating the mass culture of microalgae as a source of renewable fuels.

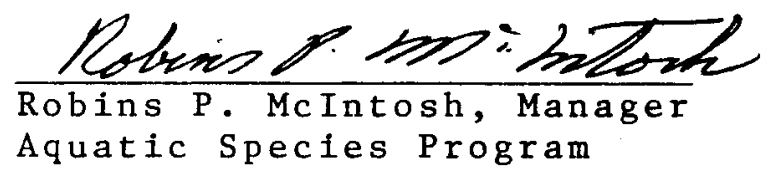




\section{SUMMARY}

\section{objective}

To determine the conditions and techniques appropriate for maximizing lipid yield from halophilic microalgae and to quantify the performance and operational parameters for a shallow raceway system.

\section{Discussion}

A shallow raceway system has been developed and constructed by the University of Hawaii. Briefly, the system concept includes shallow channels circulated at a high flow rate, containing very dense algal cultures. The entire system was covered with a bath containing a copper sulfate solution, which served to absorb incident infrared radiation and perhaps to stimulate lipid production. It was proposed that the heat accumulated by the copper sulfate solution could be utilized to power the entire system. The prototype system was enclosed on all sides to minimize contamination.

The Hawaii system was constructed with an area of $50 \mathrm{~m}^{2}$ and incorporated most, but not a11, of the original design features. Airlift pumps, restricted within 6-in. PVC pipes rather than open as in the IFP system, were used for recirculation and gas exchange. The system was covered with panels containing a 1-cmthick layer of a $5 \%$ copper sulfate solution, suspended at about $30 \mathrm{~cm}$ over the surface of the culture and slightly tilted to the south to correct for sun angle and to permit rainwater runoff. Cultures were grown at a depth of $7.5 \mathrm{~cm}$ and circulated at a velocity of about $25 \mathrm{~cm} / \mathrm{sec}$. The cultures were not fully enclosed and, after initial testing, the copper sulfate panels were removed. The panels were effective as infrared shields, but their overall effect on production was judged to be detrimental because they also removed about $50 \%$ of the photosynthetically active radiation (400-700 nm wavelength). The net negative effect of these panels on production was later confirmed by factorial experiments in four smaller cultures of similar design, each with $9.2 \mathrm{~m}$ of surface area, constructed in 1982 and 1983 at the same site. The same experiments confirmed, however, that the panels made a significant contribution to temperature control in the cultures.

A major contribution of the Hawaii project has been the development of a system that introduces ordered vertical mixing into the culture as a by-product of stream flow. Small foils, similar in design to airplane wings, were suspended in the flowstream at a relatively high angle of attack. Vortices were generated at the tips of each of these foils and were propagated downstream. Arrays of foils were positioned every $1.2 \mathrm{~m}$ along the culture flume. Observations of the vortex rotation rates indicated that cells were exposed to a light-dark cycle time of 1 to 2 seconds in this mixing regime, 
compared to the 10 seconds predicted for a purely turbulent regime. In addition, light-dark cycling was provided in a patterned manner rather than on a random basis. Productivity in a system employing the foils was increased by a factor of 2.2 over the productivity in the same system without the foils, but again it is not completely clear that light modulation was solely responsible for the increased productivity.

Conclusions

A fractional factorial experimental design was used to determine the maximum production and photosynthetic efficiency that could be achieved in shallow algal mass culture systems (SAMCS) of the marine diatom Phaeodactylum tricornutum. Dilution rate and $\mathrm{CO}_{2}$ supply were found to be the most important system parameters. Maximum production was found to be about $25 \mathrm{~g}$ dry wt $\mathrm{m}^{-2} \mathrm{~d}^{-1}$. This production corresponded to a photosynthetic efficiency of $5.6 \%$. These figures are $50-100 \%$ better than the production rates achieved in earlier P. tricornutum cultures using conventional culture techniques. The results are consistent with a theoretical model of the impact of the flashing light effect on algal mass culture production. This model preducts that at the typical irradiances in Hawail, full utilization of the flashing light effect should enhance production by $70 \%$ to over $200 \%$. It was concluded that the use of foil arrays in the experimental flume creates systematic vertical mixing on a time scale suitable for utilizing the flashing light effect. Harvesting $\underline{p}$. tricornutum cells is accomplished straightforwardly by adding approximately $0.5 \mathrm{mM} \mathrm{NaOH}$ to the culture. With this addition the cells rapidly flocculate and settle out with a 1 most $100 \%$ efficiency. Production of $P$. tricornutum culture is probably limited by temperature. P. tricornutum cannot survive at temperatures in excess of $25^{\circ} \mathrm{C}$ in outdoor mass cultures. Growth of mesophilic species in the temperature range $30-35^{\circ} \mathrm{C}$ may well result in even higher production than that achieved with $\underline{P}$. tricornutum. 
TABLE OF CONTENTS

1.0 Introduction . . . . . . . . . . . . . . . . . . . 1

1.1 Historical Background . . . . . . . . . . . . . . . 1

1.2 Theoretical Background ................... 1

2.0 Materials and Methods ................... 3

2.1 The Culture System . . . . . . . . . . . . . 3

2.2 Analytical Data ................... . . . . . . . . . .

3.0 Results. . . . . . . . . . . . . . . . . . . . . 14

3.1 Task I: Operational Parameter Screening. . . . . . . . . .14

3.2 Fractional Factorial Analysis - Sample Response . . . . . . .19

3.3 Fractional Factorial Analysis - Biological Effects. . . . . .19

3.4 Selection of Variables for Further Study . . . . . . . . . 23

3.5 Task II: Yield Optimization. . . . . . . . . . . . . . 27

3.6 Task III: Analysis, Modeling, \& Laboratory Support Studies . .32

3.7 Theoretical Analysis of Potential Advantage of

Flashing Light Effect for Mass Culture Work . . . . . . . . . 32

3.8 Algal Harvesting Strategies . . . . . . . . . . . . . 38

3.9 Suitability of Other Strains of Phaeodactylum . . . . . . . 39

3.10 Laboratory Support Studies. . . . . . . . . . . . . . . . 39

3.11 Task IV: Performance Sensitivity Analysis. . . . . . . . .45

4.0 References . . . . . . . . . . . . . . . . . . . 47 


\section{LIST OF FIGURES}

$\underline{\text { Page }}$

1-1 Design of a single foil indicating mechanism of vortex

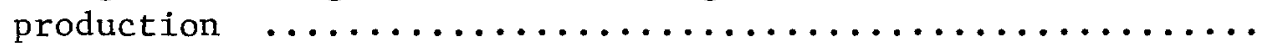

1-2 Positioning of individual foils in foil array. Lower figure indicates positioning of array in the flume. $D$ is the depth of the water. Arrows indicate rotational direction

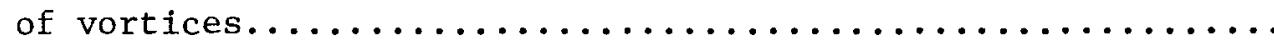

2-1 Perspective to algal production flume showing location of heat exchanger, lift box, drain box, and airlift system ....

2-2 Cross section of flume modules indicating positioning of chill pipes, airlift, and $\mathrm{CO}_{2}$ feed.................. 8

2-3 Detail of recirculation and airlift system $\ldots \ldots \ldots \ldots \ldots \ldots$

2-4 Schematic of seawater supply system and algal storage tank... 11

2-5 Overhead perspective of flume indicating horizontal dimensions and positioning of $\mathrm{CO}_{2}$ feed and airlifts......... 12

3-1 Normal plot of factor effects on observed culture

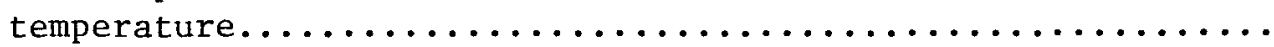

3-2 Normal plot of factor effects on carbon production......... 24

3-3 Normal plot of factor effects on photosynthetic efficiency... 25

3-4 Percentages of dissolved carbon dioxide, bicarbonate ion and carbonate ion as a function of $\mathrm{pH}$ at $0^{\circ} \mathrm{C}$. Continuous

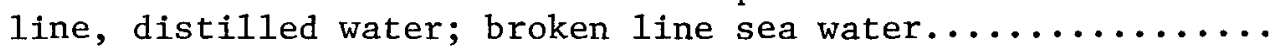

3-5 Production of carbon in experimental flumes as a function of $\mathrm{pH}$ and dilution rate. Curved lines are equation $4 \ldots \ldots \ldots$

3-6 Photosynthetic efficiency in experimental flumes as a function of $\mathrm{pH}$ and dilution rate. Curved lines are expansion similar to equation $4 \ldots \ldots \ldots \ldots \ldots \ldots \ldots \ldots \ldots \ldots \ldots \ldots \ldots \ldots$

3-7 Ratio of growth rate under ideal flashing light regime to growth rate in absence of flashing light effect as a function of incident irradiance and areal chl a concentration using equations 11 and $12 \ldots \ldots \ldots \ldots \ldots \ldots$ 
2-1 Flume specifications . . . . . . . . . . . . . . . . . 4

3-1 A fractional factorial experimental design for eight factors in 16 runs . . . . . . . . . . . . . . . . . . . 15

3-2 Raceway Experimentation Schedule Fractional Factorial Analysis . . . . . . . . . . . . . . . . . . . . 16

3-3 Block effects of measured environmental variables . . . . . . . 18

3-4 Confounding of effects in the fractional factorial analysis . . . 20

3-5 Summary of factor effects on various culture responses. Effects are given in standard deviations . . . . . . . . . . 21

3-6 Most important factors affecting production and photosynthetic efficiency . . . . . . . . . . . . . . . 26

3-7 Parameter values used to characterize the Bannister (39) mode1 . . . . . . . . . . . . . . 35

3-8 Growth rate and lipid content of six strains of 40

P. tricornutum. Growth rates are in units of d-1 . . . . . . . 40

3-9 Results of lipid analyses on flume $P$. tricornutum culture on eight consecutive days ...... . . . . . . . . . 4 41

3-10 Summary of flume experiments to determine reproducability of production results .................... 4 42

3-11 Results of adding seleniun and nickel to cultures of P. tricornutum 
SERI/STR-231-2206

\section{SECTION 1.0}

\section{INTRODUCTION}

\subsection{HISTORICAL BACKGROUND}

Microalgae are attractive as biomass producers because they generally exhibit higher yields and photosynthetic efficiencies than terrestrial plants. In addition, many species of microalgae produce high concentrations of intracellular oils as energy storage compounds. Microalgae are projected from laboratory scale experiments to be capable of producing over 100 barrels of liquid fuel per acre-year. Most pilot-scale mass culture systems, operated at depths of greater than $20 \mathrm{~cm}$, have shown peak average yields of around $15 \mathrm{dry}$ ash free grams $\mathrm{m}^{-2} \mathrm{~d}^{-1}$. This project is based on the premise that operation at less than $15 \mathrm{~cm}$ depth will result in significantly higher productivities.

Research on this problem began at the University of Hawaii under SERI subcontract on February 15, 1980 under the title "Research, Development, and Demonstration of Algal Production Raceway (APR) Systems for the Production of Hydrocarbon Resources." Work during the first two and one-half years resulted in the collection of a great deal of laboratory data on the performance of Phaeodactylum tricornutum; the design, construction, and operation of one $48 \mathrm{~m}^{2}$ continuous flume; the development of predator control techniques and baseline performance characteristics for the flume; and the construction of four $9.2 \mathrm{~m}^{2}$ experimental flumes. During the past year these four flumes were operated in a factorial design experiment to determine the maximum sustainable biomass yields achievable with $\underline{P}$. tricornutum cultured in shallow flume systems. Secondary goals of the past year's work were to 1) gain an understanding of the mechanisms and conditions which lead to high productivity, photosynthetic efficiency, and lipid yield, and 2) analyze the performance in response to operational improvements projected to arise from further research and development. It was expected that these goals would be achieved through work on the following four tasks

I Operational Parameter Screening

II Yield Optimization

II Analysis, Modeling and Laboratory Support Studies

IV Performance Sensitivity Analysis

\subsection{THEORETICAL BACKGROUND}

It has been known for a number of years that the efficiency of light utilization by phytoplankton can be markedly increased by exposing the cells to alternating periods of 1 ight and dark (1-7). More recently, a number of investigators have explored this 
phenomenon both experimenta11y and theoretical1y (8-15). Although early work $(2-4)$ indicated that flash periods as short as $10 \mu \mathrm{s}$ were needed to take maximum advantage of the flashing light effect, it is now clear that flash periods as 10 ng as $10-70 \mathrm{~ms}$ may still result in significant enhancements of photosynthetic efficiencies $(14,16)$, and Marra (13) has reported increases up to $87 \%$ in photosynthesis by simply modulating the irradiance on alga 1 cells on a time scale ranging from minutes to hours. It seems reasonable to postulate that the physiological mechanisms responsible for these observed photosynthetic enhancements differ substantially over the vast range of time scales involved. However, regardless of the physiological mechanisms involved, it is clear that photosynthetic efficiencies may be enhanced by a factor of two or more by modulating or flashing the incident light on an appropriate time scale. For the case of flashing light, it is apparent that the maximum duration of the light pulse which produces the highest photosynthetic efficiency will be negatively correlated with light intensity at light intensities greater than or equal to $I_{K}$, the light intensity above which photosynthetic efficiency begins to decrease under constant illumination ( 17 ), and that the duration of the dark period must lie somewhere in the approximate range 0.1-10s (18).

A critical question in algal mass culture work is whether a physical mechanism exists for taking advantage of the flashing light effect in a practical way. As noted by Phillips and Myers (14), "Any attempt to grow algae in sunlight will experience some gain by turbulence. The feasability of increasing the turbulence will depend upon the extent of the gain in growth as compared to the increased power requirements of stirring or pumping the suspension." Unfortunately, it does not appear that merely producing random turbulence is sufficient to take advantage of the flashing light effect to any significant degree in a mass culture system. Powel1, Chaddock, and Dixon (15) reached this conclusion based on theoretical calculations, and Miller et al. (19) commented that, "Utilization of the flashing light effect for improvement of photosynthetic efficiency of dense algal cultures requires a nonrandom mixing pattern-one in which cells are exposed to regular sequences of 1 ight and darkness..."

In the past two types of experimental systems have been studied as possible means of utilizing the flashing light effect. A so-called Couette device was used by Miller et al. (19), Davis et al. (20), and Howell, Fredrickson, and Tsuchiya (21). The Couette device consists of two concentric, circular cylinders, the inner of which can be rotated at a selected speed. The system is 111 uminated either from the outside or inside, and the culture is grown in the gap between the cylinders. The flow pattern in the culture medium is complex, but sufficiently nonrandom that a Hyslematlc flashing 1 ight effect is achieved. Howel1, Fredrickson, Ind Tuuchlya (2l) estimated the period of the light-dark cycles in cheir Hyslom to be about $40 \mathrm{msec}$. More recently, oswald et a1. (22) 
and Shelef, Sabanas, and oswald (23) have described a chemostattype system called an algatron, which consists of a drum that is rotated about its vertical axis. The algal culture is contained within the drum as a film a few centimeters thick on the inside wall of the drum, and is retained against the wall by centrifugal force. A light source is mounted inside the drum, and a row of stee1 strips extending to within $0.5-1.0 \mathrm{~mm}$ of the inside wall produces highly turbulent wakes, which extend in spirals around the culture. The photosynthetic efficiencies which can be achieved with the Couette device and algatron are on the order of $10 \%(17)$.

It seems unlikely that either the Couette device or the algatron will prove to be a practical means of utilizing the flashing light effect. Both devices are mechanically complex, and the power requirements for operating them may well offset any increase in production, both from a financial and an energetic standpoint. As noted by Fredrickson and Tsuchiya (17), "Clearly some device that is mechanically more simple than the foregoing devices is required." The mechanism we have devised to produce systematic vertical mixing in our flume is illustrated in Figures $1-1$ and $1-2$. The device consists of a series of foils similar in design to airplane wings placed across the flume. As water flows over and under these foils, a pressure difference is created as illustrated in Figure 1-1. At the tips of the foil, the flow of water from the high pressure region below the foil to the low pressure region above the foil creates a vortex off each tip of the foil. If the foils are properly spaced along a suitable supporting structure (Figure 1-2), the vortices on adjacent foils rotate in opposite directions and thus reinforce each other. The width of each foil and the gap between foils are equal to the depth of the culture, so that circular vortices created by the foils effectively mix the culture from top to bottom (Figure 1-2). The system of vortices with rotational axes parallel to the direction of flow produces the sort of systematic mixing necessary to produce the flashing light effect.

SECTION 2.0

MATERIALS AND METHODS

\subsection{THE CULTURE SYSTEM}

The flumes utilized in our studies consisted of one $48 \mathrm{~m}^{2}$ continuous flume and four $9.2 \mathrm{~m}^{2}$ continuous flumes. The $48 \mathrm{~m}^{2}$ flume is illustrated in Figure 2-1, and specifications for the $48 \mathrm{~m}^{2}$ flume appear in Table 2-1. The flume is of a modular construction. The base channel module is a $1.2 \times 2.4 \mathrm{~m}$ molded fiberglass trough with $10 \mathrm{~cm}$ sides. The sides are raised an additional $23 \mathrm{~cm}$ with a plywood extension, coated with acrylic resin (Figure 2-2). AIl seams are covered with fiberglass cloth and resin. The channel 


\begin{tabular}{|c|c|c|}
\hline & Flume & Specifications \\
\hline Construction & & $\begin{aligned} \text { Modular: } & 1 \text { liftbox module } \\
& 1 \text { turning box/heat exchanger } \\
& 1 \text { drainbox } \\
& 14 \text { channel modules } \\
& 3 \text { recirculation pipes/airlifts }\end{aligned}$ \\
\hline $\begin{array}{l}\text { Centerline channel length } \\
\text { Area } \\
\text { Depth range } \\
\text { Operating depth }\end{array}$ & & $\begin{array}{l}37.2 \mathrm{~m} \\
48.39 \mathrm{~m}^{2} \\
5-28 \mathrm{~cm} \\
7.75 \mathrm{~cm} \text { (standard deviation } 0.74 \mathrm{~cm}, 91 \text { mea- } \\
\text { surements), with upper leve1 electrode set at } \\
7.6 \mathrm{~cm} .\end{array}$ \\
\hline $\begin{array}{l}\text { Volume at operating depth } \\
\text { Flow rate } \\
\text { Slope }\end{array}$ & & $\begin{array}{l}4150 \mathrm{~L} \\
30 \mathrm{~cm} / \mathrm{s} \text { (circuit time } 120 \mathrm{~s} \text { ) } \\
0.16 \mathrm{~cm} / \mathrm{m}\end{array}$ \\
\hline & Module & Specifications \\
\hline $\begin{array}{l}\text { Liftbox } \\
\text { Construction } \\
\text { Area } \\
\text { Volume at operating depth }\end{array}$ & & $\begin{array}{l}2-\mathrm{cm} \mathrm{plywood} \mathrm{painted} \mathrm{with} \mathrm{fiberglas} \mathrm{resin} \\
1.49 \mathrm{~m}^{2} \\
115 \mathrm{~L}\end{array}$ \\
\hline $\begin{array}{l}\text { Area } \\
\text { Volume at operating depth }\end{array}$ & & $\begin{array}{l}2-\mathrm{cm} \text { plywood painted with fiberglas resin } \\
3.2 \text { tubular titanium } \\
\text { PVC fittings } \\
3.73 \mathrm{~m}^{2} \\
290 \mathrm{~L}\end{array}$ \\
\hline $\begin{array}{l}\text { Drainbox } \\
\text { Construction } \\
\text { Area } \\
\text { Volume at operating depth }\end{array}$ & & $\begin{array}{l}2-\mathrm{cm} \text { plywood painted with epoxy resin } \\
1.49 \mathrm{~m}^{2} \\
220 \mathrm{~L}\end{array}$ \\
\hline $\begin{array}{l}\text { Channel modules } \\
\text { Construction } \\
\text { Area } \\
\text { Volume at operating depth }\end{array}$ & & $\begin{array}{l}\text { Spray-molded fiberglas } \\
\text { PVC reinforcements } \\
2-\mathrm{cm} \text { plywood painted with fiberglas resin } \\
2.98 \mathrm{~m}^{2} \text { each module, } 41.67 \mathrm{~m}^{2} \text { total } \\
230 \mathrm{~L} \text { each module, } 3225 \mathrm{~L} \text { total }\end{array}$ \\
\hline $\begin{array}{l}\text { Recirculation } \\
\quad \text { Construction }\end{array}$ & & $\begin{array}{l}15 \mathrm{~cm} \text { i.d. PVC pipe } \\
\text { PVC fittings } \\
\text { epoxy resin } \\
\text { silicone glue } \\
\text { (three separate pipes, nested, with separate } \\
\text { airlifts) }\end{array}$ \\
\hline $\begin{array}{l}\text { Volume: } \\
\text { Airlift pumping rate: } \\
\text { Airlift life height: } \\
\text { Airlift air consumption rate: }\end{array}$ & & $\begin{array}{l}300 \mathrm{~L} \\
690 \text { liter } \mathrm{min}^{-1} \text { each lift, } 2070 \text { liter } \min ^{-1} \text { total } \\
163 \mathrm{~cm} \text { (air outlet to water surface at } \\
\text { operating depth) } \\
550 \text { liters min }\end{array}$ \\
\hline
\end{tabular}




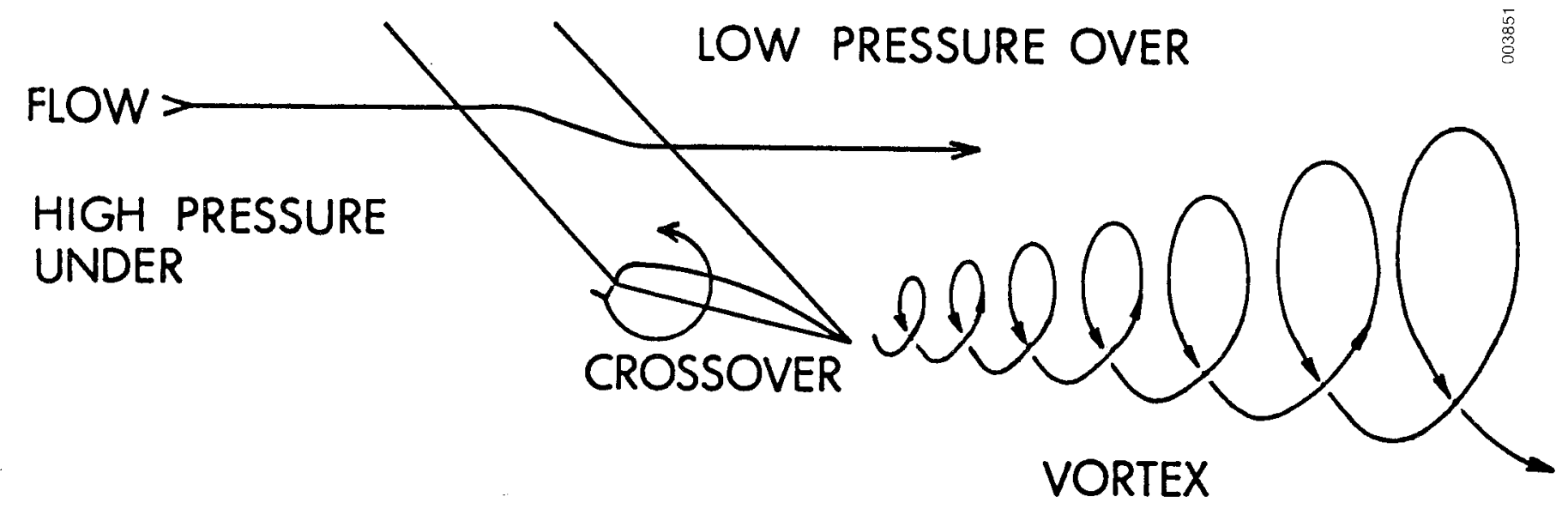

Figure 1-1. Design of a single foil indicating mechanism of vortex production. 

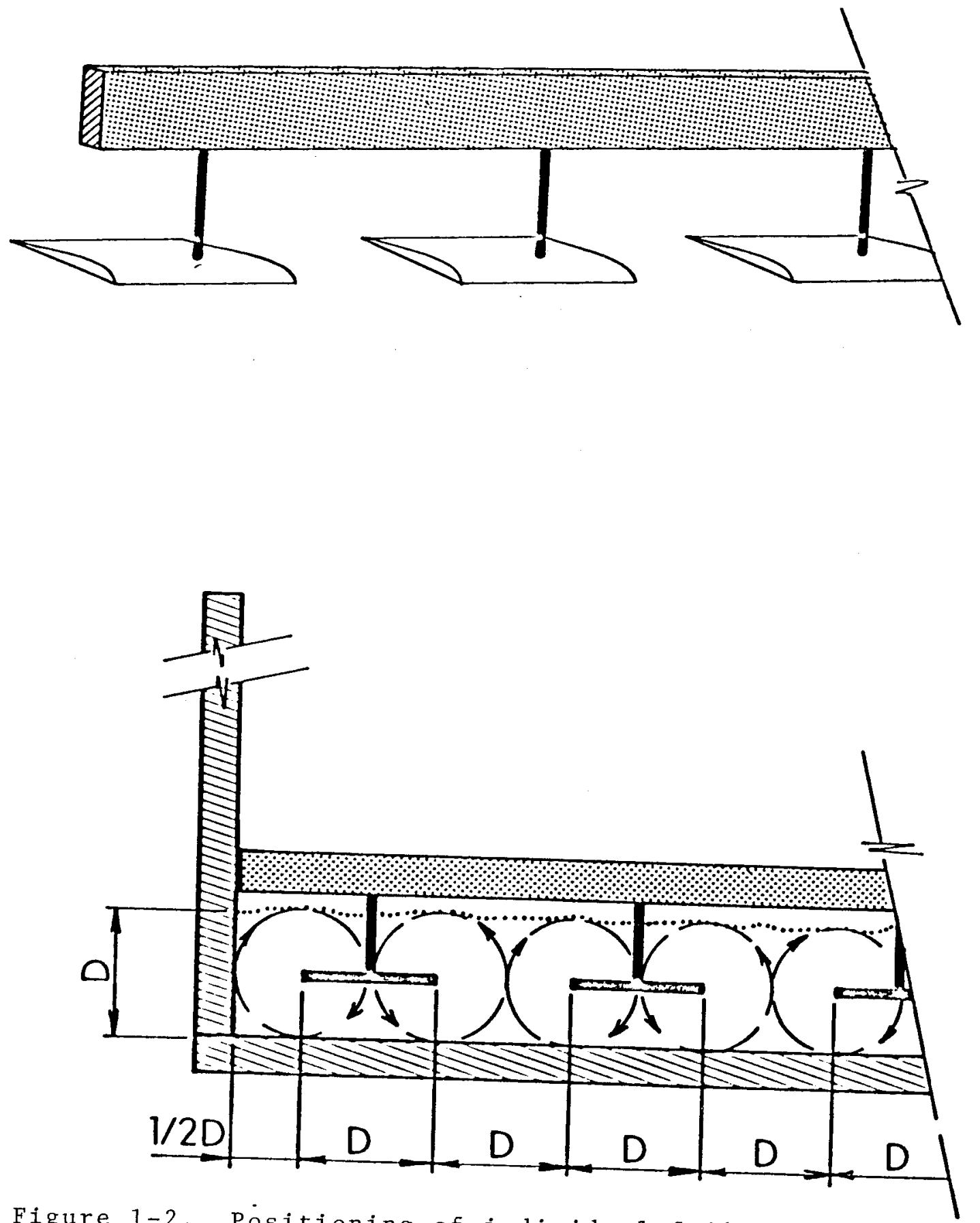

Figure 1-2. Positioning of individual foils in foil array. Lower figure indicates positioning of array in the flume. D is the depth of the water. Arrays indicate rotational direction of vortices. 


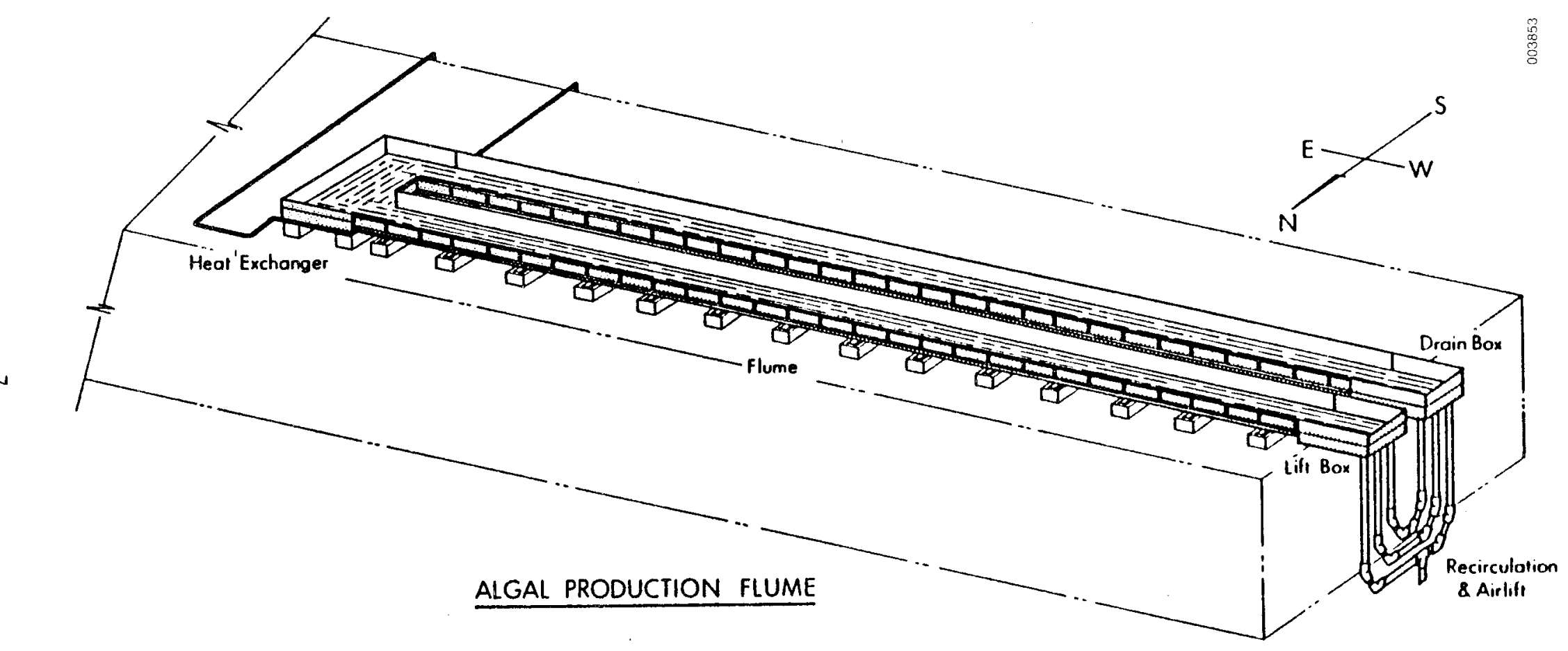

Figure 2-1. Perspective to algal production flume showing location of heat exchanger, lift box, drain box, and airlift system. 

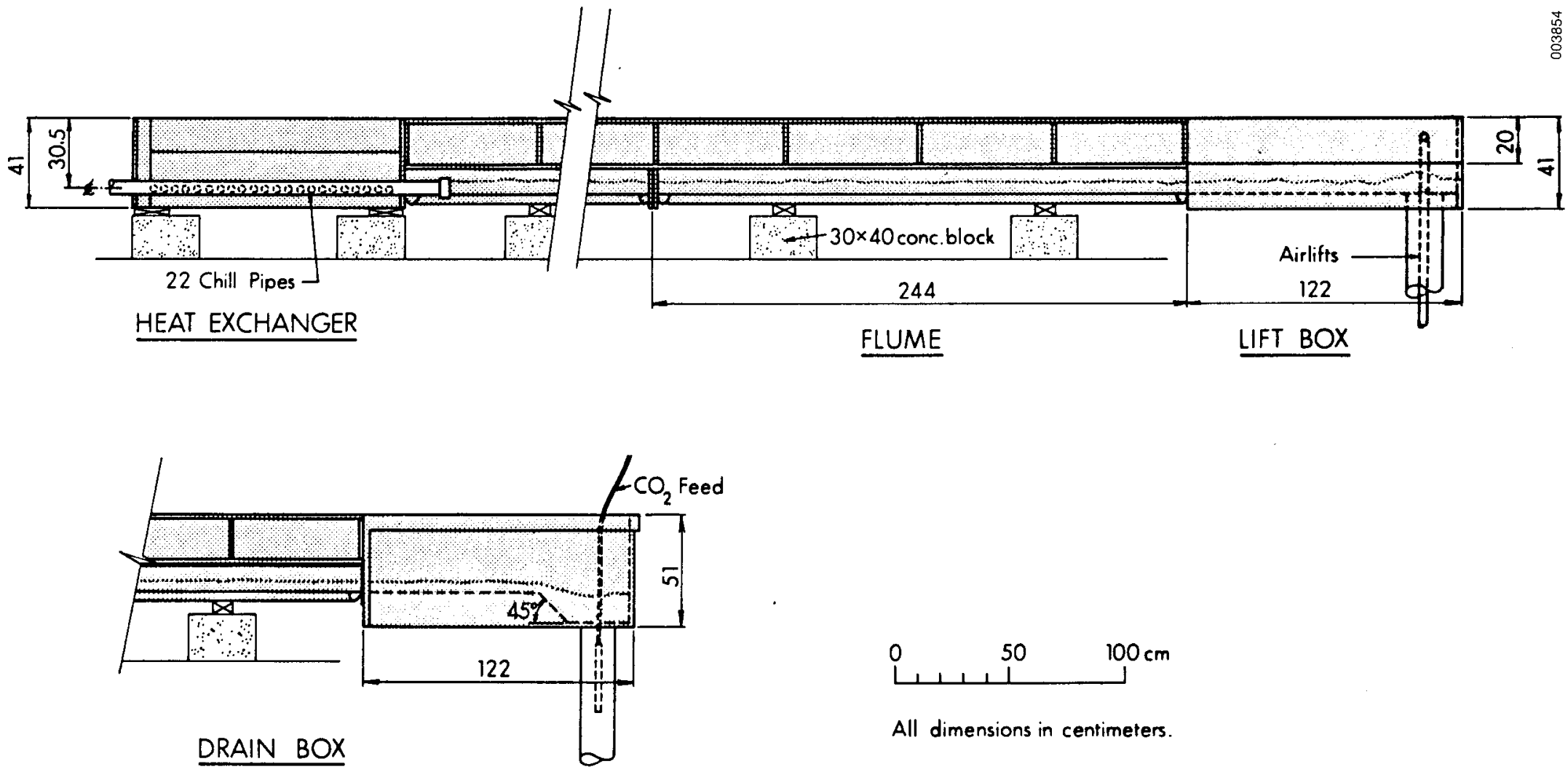

All dimensions in centimeters.

Figure 2-2. Cross section of flume modules indicating positioning of chill pipes, airlift, and $\mathrm{CO}_{2}$ feed. 
modules are reinforced with split $7.5 \mathrm{~cm}$ diameter polyvinyl chloride (PVC) pipe, and are mounted on $5 \times 10 \mathrm{~cm}$ wooden rails supported by concrete blocks.

In addition to the channel modules, there are two end-box modules and a heat exchanger module which also serves as a turning box. one end-box serves as a drain box, the other as a lift box, and they are connected by three recirculation pipes with airlifts. The drain box (Figure 2-2) includes a small 15-cm deep sump to provide for even flow. The airlifts discharge directly onto the level surface of the flume in the lift box (Figure 2-2). The recirculation pipes (Figure 2-3) are $15 \mathrm{~cm}$ outside diameter PVC pipe turned in a U-shape using $45^{\circ}$ PVC elbows to reduce flow resistance over that which would be introduced by $90^{\circ}$ elbows. Each of the two inner recirculation pipes has a small drain port at the bottom of the $U$; there is a $15-\mathrm{cm}$ valve and drain line located in the outermost recirculation pipe which allows the culture to be transfered to the culture storage tank (Figure 2-4). The airlifts are fed by $2.4 \mathrm{~cm}$ PVC pipes which discharge $1.4 \mathrm{~m}$ below the water surface. Oil-free air is supplied by a watersealed, water 1 ubricated compressor driven by a 3.5 horsepower motor. The heat exchanger consists of twenty-two $2.5 \mathrm{~cm}$ titanium pipes mounted in the $1.2 \times 3 \mathrm{~m}$ turning box (Figure 2-5). When cooling is required, cold water is circulated through the titanium pipes from the chiller. Activation of the chiller is maintained under computer control.

A seawater system (Figure 2-4) provides capabilities for adding seawater to the flume, obtaining seawater for laboratory use, partially or completely draining the flume, and storing the culture or seawater. Seawater is drawn from a 45-m-deep well. The seawater is filtered through coral rubble, and is therefore very low in particulate organic matter. Levels of major inorganic nutrients are typical1y $50 \mu \mathrm{M}$ ammonium and $0.8 \mu \mathrm{M}$ phosphate. The inlet to the seawater pump is from the saltwater well or from the storage tanks. The outlet is to the flume, to the utility outlet, or to waste. The flume can be drained into the culture storage tank through the 15-cm PVC pipe using a manual valve, and pumped from that tank to any of the outlet ports, or discarded by gravity through the waste port. Wastewater is discharged into an underground sump excavated in the coral rubble.

The flume incorporates a computer-based system that monitors and controls the physical and chemical environment of the culture. The system controller is a Hewlett-Packard mode1 $9845 \mathrm{~B}$ computer, which acquires data from the sensors and manipulates the control devices based on the information received. The chiller compressors, fans, and pump are controlled on the basis of the culture temperature. The seawater pump is controlled on the basis of the operator input and the output of the level detector. Carbon dioxide gas addition is controlled on the basis of pH. Draining is controlled on a time-of-day basis. The addition of a base $(0.6 \mathrm{M} \mathrm{NaOH})$ is controlled on the basis of $\mathrm{pH}$. 


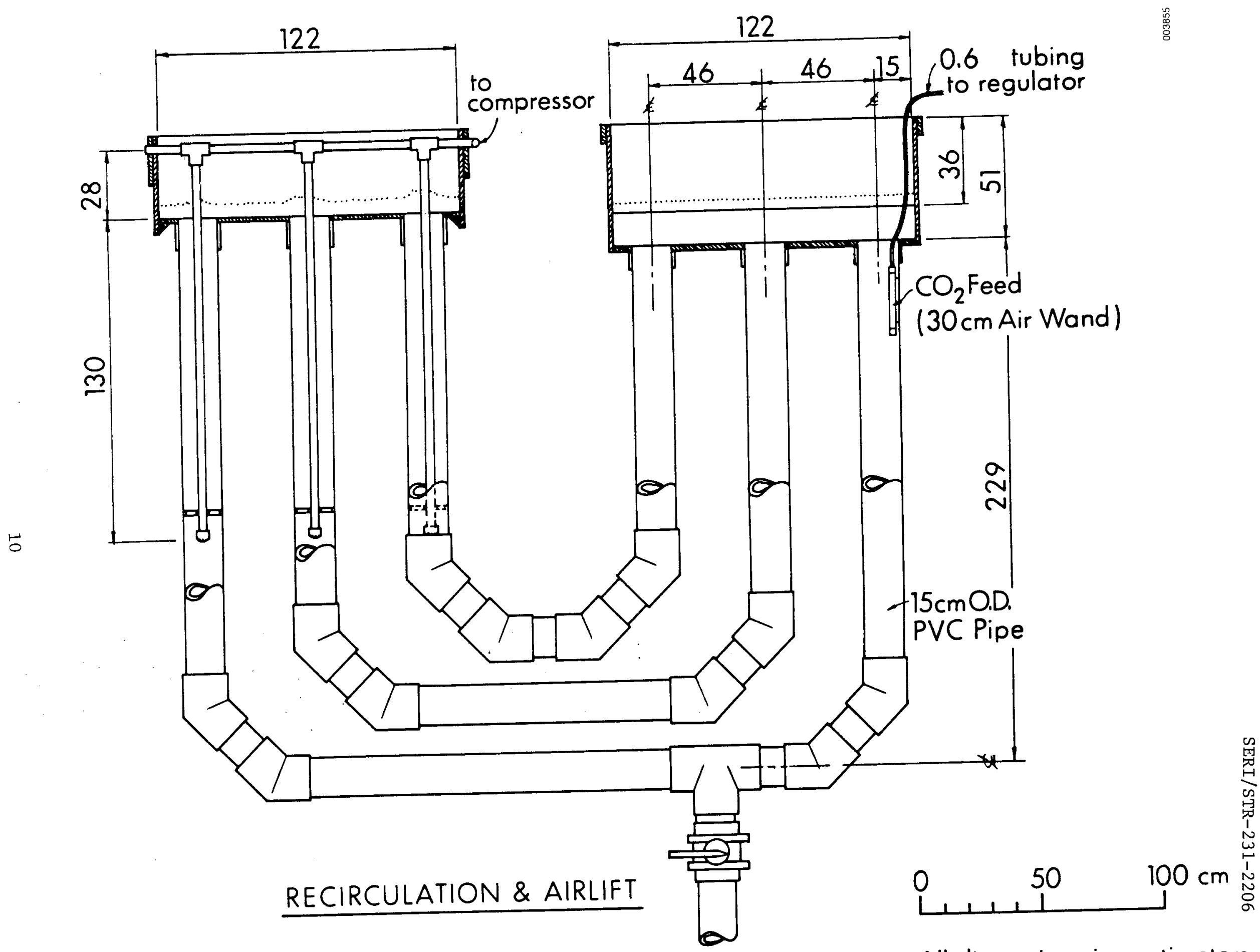

Figure 2-3. Detail of recirculation and airlift system.

All dimensions in centimeters. 


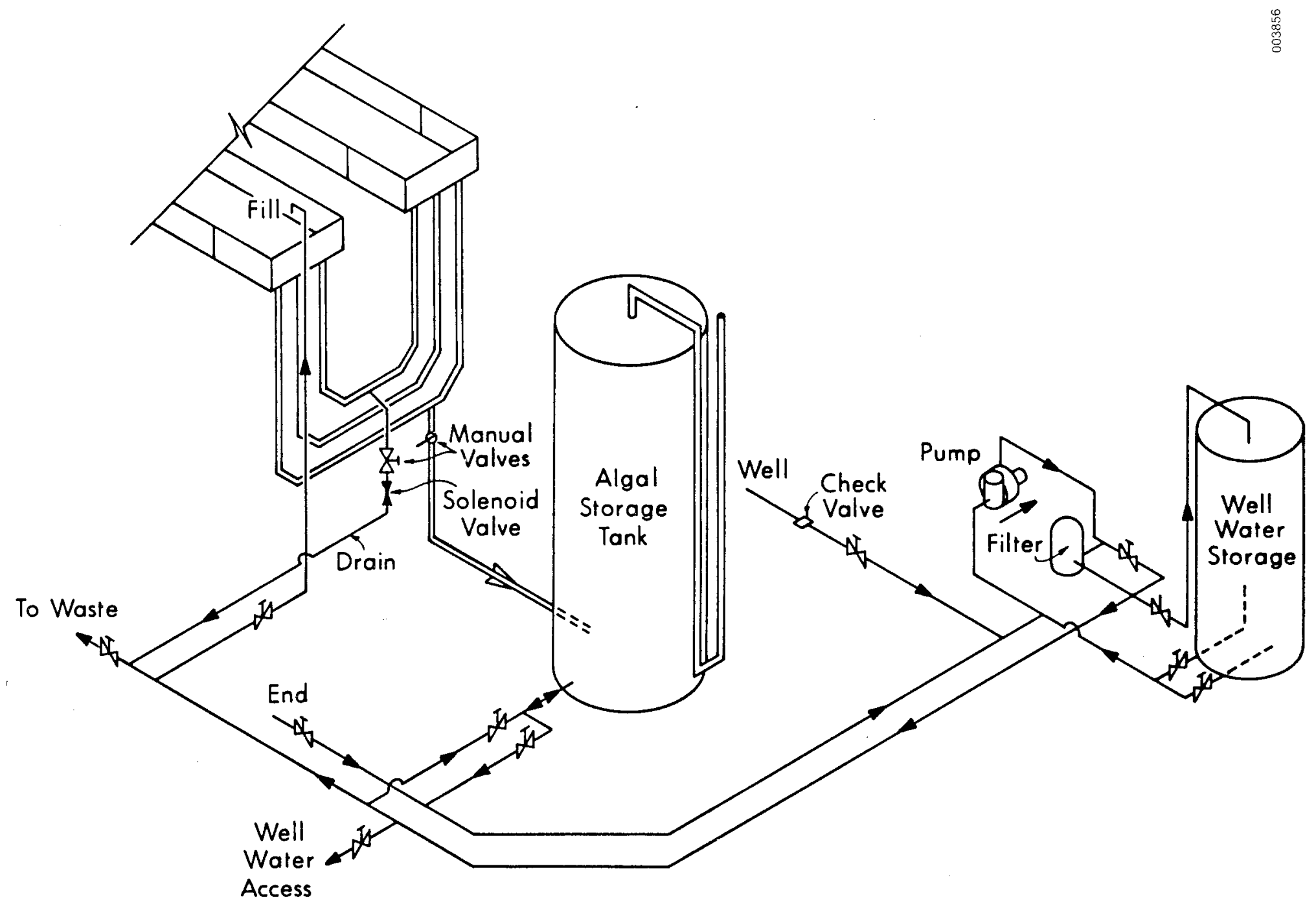

Figure 2-4. Schematic of seawater supply system and algal storage tank. 


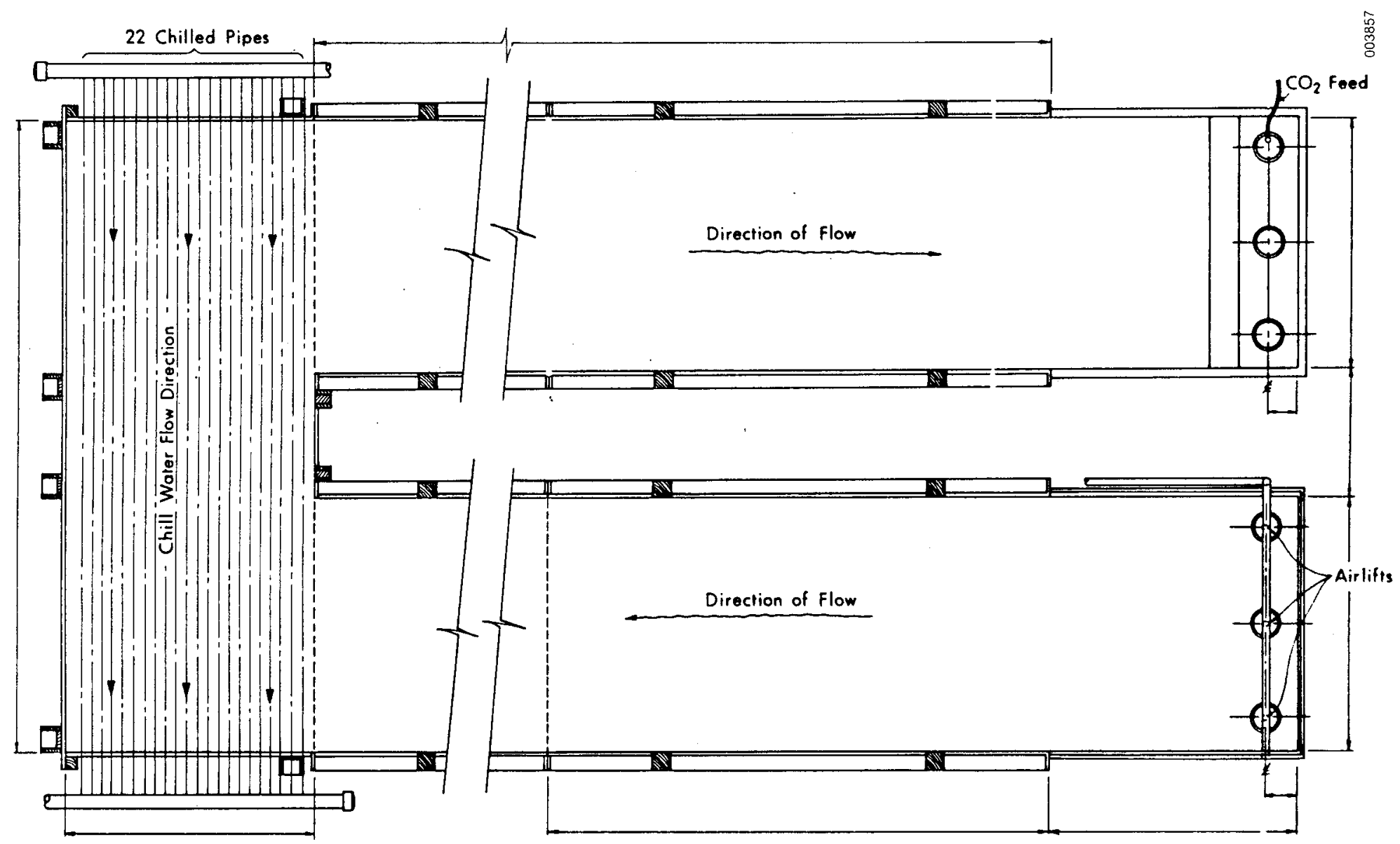

Figure 2-5. Overhead perspective of flume indicating horizontal dimensions and positioning of $\mathrm{CO}_{2}$ feed and airlifts. 
An additional, computer-independent device is also provided to protect the culture from overheating in the event of computer failure. This over-temperature control prevents the flume temperature from rising above $30^{\circ} \mathrm{C}$ by independently activating the chillers.

The four $9.2 \mathrm{~m}^{2}$ flumes are similar in design to the $48 \mathrm{~m}^{2}$ flume, but consist of two channels $7.6 \mathrm{~m}$ long by $0.6 \mathrm{~m}$ wide by $0.15 \mathrm{~m}$ deep. The channels are connected by $20 \mathrm{~cm}$ recirculation pipes; one of the two recirculation pipes of each culture contains an airlift pump which drives culture circulation. Each $9.2 \mathrm{~m}^{2}$ flume is equipped with a $\mathrm{CO}_{2}$ supply line and with a 1.5 horsepower chilling unit, which exchanges heat with the water through $6 \mathrm{~m}$ of $2.5 \mathrm{~cm}$ diameter titanium pipe. The titanium heat exchangers are U-shaped and are positioned just upstream of the downflow to one of the recirculation pipes. Temperature and $\mathrm{pH}$ sensors in the cultures supply data to the Hewlett-Packard $9845 \mathrm{~B}$ computer, which in turn controls chiller function and the $\mathrm{CO}_{2}$ supply solenoids.

The experimental results reported here were all obtained with the marine diatom Phaeodactylum tricornutum. This species was chosen as a test organism because of its known tendency to dominate outdoor mass cultures (24), its wide range of tolerance to pH, salinity and temperature $(25-28)$, its ability to withstand buffeting (29), and the fact that excretory products produced by P. tricornutum appear to be inhibitory to the growth of bacteria as well as other algae $(25,30)$. The particular strain of P. tricornutum used in these studies was obtained from the culture collection of Dr. William Thomas at the Scripps Institute of Oceanography.

\subsection{ANALYTICAL DATA}

Production in the flume was calculated from daily changes in particulate carbon ( $P C$ ) concentrations corrected for dilution due to drainage and introduction of fresh medium. Samples for PC analyses were collected on glass-fiber (GF/C) filters and analyzed on a Hewlett-Packard model $185 \mathrm{~B}$ CHN analyzer following procedures recommended by sharp (31). These carbon production numbers were converted to dry weight production by multiplying by the experimentally determined ratio of dry weight:PC. We found this ratio to be 2.0. Dry weights were measured by filtering samples onto GF/C filters and drying at $60^{\circ} \mathrm{C}$ to constant weight. The percent ash was calculated from samples also collected on GF/C filters, and combusted at $500^{\circ} \mathrm{C}$ for four hours. We found that ash accounted for less than $5 \%$ of the dry weight of $\underline{P}$. tricornutum when no silicate additions were made to the culture medium. Lipid contents were measured by a modified Bligh-Dyer extraction.

Culture $\mathrm{NH}_{4}$ concentrations were determined by the phenol-hypochlorite method. Urea concentrations were determined by the same method after the samples were digested with urease for $15 \mathrm{~min}$.

Solar irradiance was measured with a Lambda model LI-1905B quantum 
sensor, which has a nearly flat response to light in the wavelength range 400-700 nm. Visible quantum fluxes were converted to energy fluxes using the spectral distribution of sunlight (32). The conversion ratio was $19.5 \mu \mathrm{Einst}$ per calorie. The caloric content of the product algae was calculated assuming a heat of combustion of $6225 \mathrm{cal} / \mathrm{g}$ dry wt (29), and solar energy conversion efficiencies were calculated based on this caloric content and the incident energy flux of visible light.

SECTION 3.0

RESULTS

\section{I TASK I: OPERATIONAL PARAMETER SCREENING}

objective: - To perform blocked fractional factorial biomass yield experiments on eight operational parameters using four $9.2 \mathrm{~m}^{2}$ shallow algal mass culture systems (acronym SAMCS)

- To rank main effects and interaction effects of parameters with regard to impact on photosynthetic efficiency and biomass yield

Purpose

- To reduce the number of parameters which must be studied in detail in the optimization effort (Task II).

The fractional factorial design employed is shown in Table $3-1$, and is given in terms of the factor values in Table 3-2. In Table 3-1, each variable is assigned the + value in eight runs and the - value in eight runs. For the eight + values or the eight - values for each factor, each other factor assumes four + and four - values. Thus the effects of all other factors, if additive, will cancel in the calculation of the primary effects of a given factor.

Details of the manipulation of each experimental factor are as follows:

1. Depths were $5 \mathrm{~cm}$ or $10 \mathrm{~cm}$ mean depth. Depths varied as a function of the distance along the channel, with ranges up to $\pm 2 \mathrm{~cm}$ about the mean. Six sets of mixing foils were placed in each culture spaced at $1.5 \mathrm{~m}$ intervals to provide ordered mixing. Foil design was depth dependent: at the $5 \mathrm{~cm}$ depth the foils were $5 \mathrm{~cm}$ wide with $5 \mathrm{~cm}$ gaps between, while at the $10 \mathrm{~cm}$ depth these dimensions were $10 \mathrm{~cm}$.

2. Dilution rates are reported as the percentage of the culture removed each morning and replaced with fresh medium. Due to errors in measuring depth, dilution rates varied about the desired means.

3. Temperatures reported are the temperatures above which the 
Table 3-1. A fractional factorial experimental design for eight factors in 16 runs $\left(2_{I V}^{8-4}\right)$.

LEVEL FOR FACTOR:

\begin{tabular}{llllllllll} 
RUN & 1 & 2 & 3 & 4 & 5 & 6 & 7 & 8 \\
\hline 1 & - & - & + & - & - & + & - & + \\
2 & + & - & - & - & + & - & - & + \\
3 & + & + & + & + & - & - & - & + \\
4 & - & + & - & + & + & + & - & + \\
5 & + & - & + & - & - & - & + & - \\
6 & - & - & - & - & + & + & + & - \\
7 & - & + & + & + & - & + & + & - \\
8 & + & + & - & + & + & - & + & - \\
9 & + & + & - & - & - & + & + & + \\
10 & - & + & + & - & + & - & + & + \\
11 & - & - & - & + & - & - & + & + \\
12 & + & - & + & + & + & + & + & + \\
13 & - & + & - & - & - & - & - & - \\
14 & + & + & + & - & + & + & - & - \\
15 & + & - & - & + & - & + & - & - \\
16 & - & - & + & + & + & - & - & - \\
& + & & + & & & & & + \\
\hline
\end{tabular}


Table 3-2.

Raceway Experimentation Schedule -- Fractional Factorial Analysis

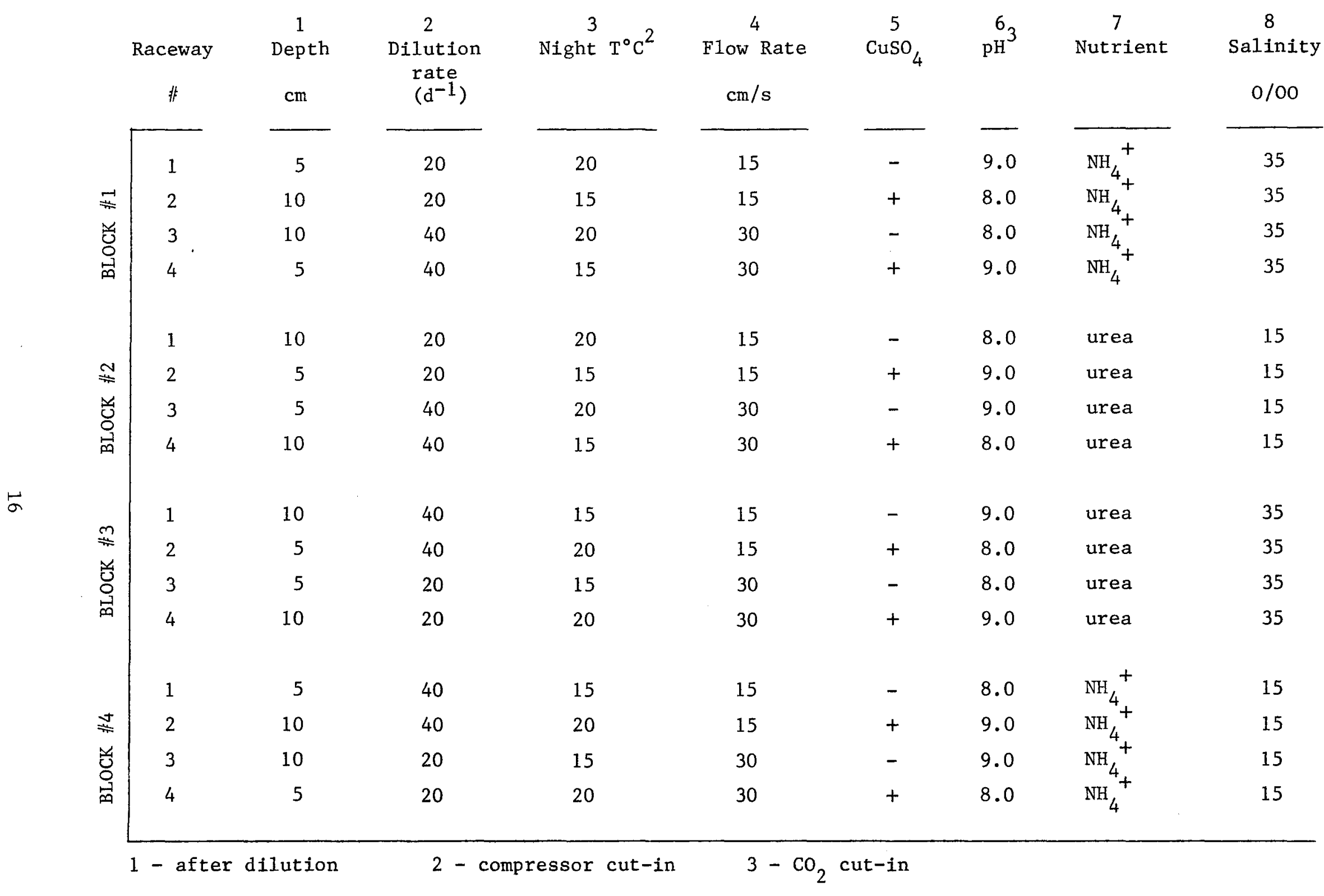


chiller for each culture was activated. Average temperatures in the cultures differed between the two treatments by $2-4^{\circ} \mathrm{C}$. Variables other than chiller activation temperature also affected the mean culture temperature (see following discussion).

4. Flow rates were 15 and $30 \mathrm{~cm} \mathrm{sec}^{-1}$, and were adjusted by varying the volume of air supplied to the airlift pump.

5. Blue light was introduced by placing double-walled Plexiglas sheets filled with $5 \%$ CuSO $_{4}$ solution above the cultures. The average light path through the $\mathrm{CuSO}_{4}$ solution was about $1 \mathrm{~cm}$.

6. The $\mathrm{pH}$ factor denotes the culture $\mathrm{pH}$ above which the $\mathrm{CO}_{2}$ supp $1 y$ solenoid was activated to supply approximately $200 \mathrm{ml} \mathrm{min}-1$ of $100 \% \mathrm{CO}_{2}$ gas.

7. Nitrogen nutrient sources were ammonium or urea, both supplied as commercial fertilizers. Concentrations were maintained at $0.5-1.5 \mathrm{mM} \mathrm{N}$. Samples for $\mathrm{NH}_{4}^{+}$and urea concentrations were taken daily. If visible comparison to a standard solution showed concentrations of 0.5 to $1.0 \mathrm{mM}$, sufficient nutrient was added to cause a $0.5 \mathrm{mM}$ increase. If concentrations were less than $0.5 \mathrm{mM}$, enough nutrient was added to cause a $1.0 \mathrm{mM}$ increase. Equimolar $(N: C)$ amounts of sodium bicarbonate were added along with the ammonium sulfate to offset alkalinity changes due to ammonium uptake.

8. Salinity was altered by diluting the 35-40\% $/ 00$ well water with tap water to achieve $15 \%$. For $35 \%$, the well water was undiluted.

Since all 16 runs could not be executed simultaneously, "blocking" of the factorial design was employed to divide the 16 runs into four sets of four runs each (Table 3-2). In such a blocked design there can be variability due to changes in uncontrolled variables between blocks. Effects of such variation cannot be distinguished from the effects of factors which have consistent signs within blocks. Table 3-3 shows the primary effects and two-factor interactions which are confounded with block effects. The table also shows the differences between the mean values for the + blocks and the mean value for the - blocks of the measured environmental variables air temperature and daily irradiance. If either of these variables, but particularly light intensity, significantly affect culture performance, substantial block effects would be expected. The block effects will be confounded with the effects of factors 7 and 8. Unmeasured variables such as well water quality could also have affected the cultures and have led to block effects. 
Table 3-3. Block effects of measured environmental variables.

\begin{tabular}{lccccccc} 
FACTOR & \multicolumn{2}{l}{ SIGN IN } & BLOCK & & TEMPERATURE EFFECT & $\frac{\text { LIGHT EFFECT }}{\mathrm{E} \mathrm{m}^{-2} \mathrm{day}^{-1}}$ \\
\hline 7 & 1 & 2 & 3 & 4 & & ${ }^{\circ} \mathrm{C}$ & \\
8 & - & + & + & - & -0.25 & -0.35 \\
$16,35,78$ & + & - & + & - & +0.35 & +3.65 \\
24 & - & - & + & + & +0.35 & +13.25 \\
\hline
\end{tabular}




\subsection{FRACTIONAL FACTORIAL ANALYSiS - SAMPLE RESPONSE}

Table 3-4 lists the 22 distinguishable effects from the fractional factorial design employed; while there were 36 total primary and two-factor effects, 21 of the second order effects were confounded in groups of three, leaving $15+7=22$ distinguishable effects. [Second order effects are referred to here by combinations of the digits referring to the factors involved; i.e. 24 is the second order effect involving dilution rate (2) and flow rate (4)]. A1so, for each set of three confounded two-factor effects, there is one other two-factor effect which differs only with respect to sign (Table 3-4).

Only primary and two-factor effects were calculated; normally, higher order effects become progressively smaller, and can be ignored. Primary effects were calculated as

$$
E(I)=\sum_{n=1}^{16} R(n) \cdot \operatorname{Sign}(I, n)
$$

where $E(I)$ is the effect due to factor $I, R(n)$ is the measured response in $r$ un $n$, and $\operatorname{Sign}(I, n)$ is the sign of factor $I$ in $r u n$ $\mathrm{n}(+1$ or -1$)$. Two-factor effects were calculated as

$$
E(I, J)=\sum_{n=1}^{16} R(n) \cdot \operatorname{Sign}(I, n) \cdot \operatorname{Sign}(J, n)
$$

To demonstrate the data analysis technique in an idealized case, we have selected a culture response which should be affected by only certain of the factors employed. The example presented here is culture temperature; other examples can be found in Table 3-5. The effects calculated according to equations 1 and 2 will ideally be distributed normally about their mean if all effects are random. The cumulative frequency distribution of these effects, when plotted on probability paper, should appear linear. Any effects at the tails of these curves which fall outside of this linear relationship are thus greater than would be predicted by probability. In the case of temperature, two factors had considerable effects on culture temperature, 3 (chiller cut-in) and 5 ( $\mathrm{CuSO}_{4}$ panels) (Figure 3-1). These are, in fact, the variables which we would most expect to influence culture temperature. None of the other variables, with the possible exception of 1 (culture depth, hence volume) would be expected to significantly affect temperature. [Factor 1 was in fact the next most significant variable (Table 3-5)].

\section{3 FRACTIONAL FACTORIAL ANALYSIS - BIOLOGICAL EFFECTS}

The effects of the various factors on biomass and lipid production 
Table 3-4. Confounding of effects in the fractional factorial analysis.

\begin{tabular}{|c|c|}
\hline EFFECT & EQUIVALENT TO: \\
\hline 1 & \\
\hline 2 & \\
\hline 3 & \\
\hline 4 & \\
\hline 5 & \\
\hline 6 & \\
\hline 7 & BLOCK \\
\hline 8 & BLOCK \\
\hline 12 & $(-37,-46,-58)$ \\
\hline 13 & $48,56(-27)$ \\
\hline 14 & $38,57(-27)$ \\
\hline 15 & $36,47(-28)$ \\
\hline 16 & $35,78(-24)$ BLOCK \\
\hline 17 & $45,68(-23)$ \\
\hline 18 & $34,67(-25)$ \\
\hline 23 & $(-17,-45,-68)$ \\
\hline 24 & $(-16,-35,-78)$ BLOCK \\
\hline 25 & $(-18,-34,-67)$ \\
\hline 26 & $(-14,-38,-57)$ \\
\hline 27 & $(-13,-48,-56)$ \\
\hline 28 & $(-15,-36,-47)$ \\
\hline 37 & $46,58(-12)$ \\
\hline
\end{tabular}


Table 3-5. Sumnary of factor effects on various culture responses. Effects are given in standard deviations.

\section{RESPONSE}

1. Biomass Production

2. Photosynthetic Efficiency

3. Lipid Production

4. Particulate Carbon Concentration

5. Temperature

6. $\mathrm{pH}$

7. Salinity

\begin{tabular}{cccccccc}
\hline$\underline{1}$ & $\underline{2}$ & $\underline{3}$ & $\underline{4}$ & $\underline{5}$ & $\underline{6}$ & $\underline{7}$ & $\underline{8}$ \\
2.12 & -0.86 & 0.80 & 0.60 & -0.51 & -0.99 & -0.66 & -0.14 \\
2.13 & -0.74 & 0.76 & 0.41 & -0.57 & -1.28 & -0.39 & -0.51 \\
1.91 & -1.14 & 0.76 & 0.03 & 0.09 & -0.77 & 0.36 & 0.11 \\
-0.58 & -1.95 & 0.52 & 0.36 & -0.04 & -1.03 & -0.69 & 2.48 \\
0.68 & -0.53 & 2.39 & 0.49 & -3.42 & -0.11 & 0.12 & 0.44 \\
0.12 & 0.04 & -0.14 & -0.50 & -1.61 & 2.31 & -0.81 & -1.54 \\
-0.69 & -0.38 & 0.47 & 1.65 & 1.14 & -0.58 & -1.26 & -2.33
\end{tabular}




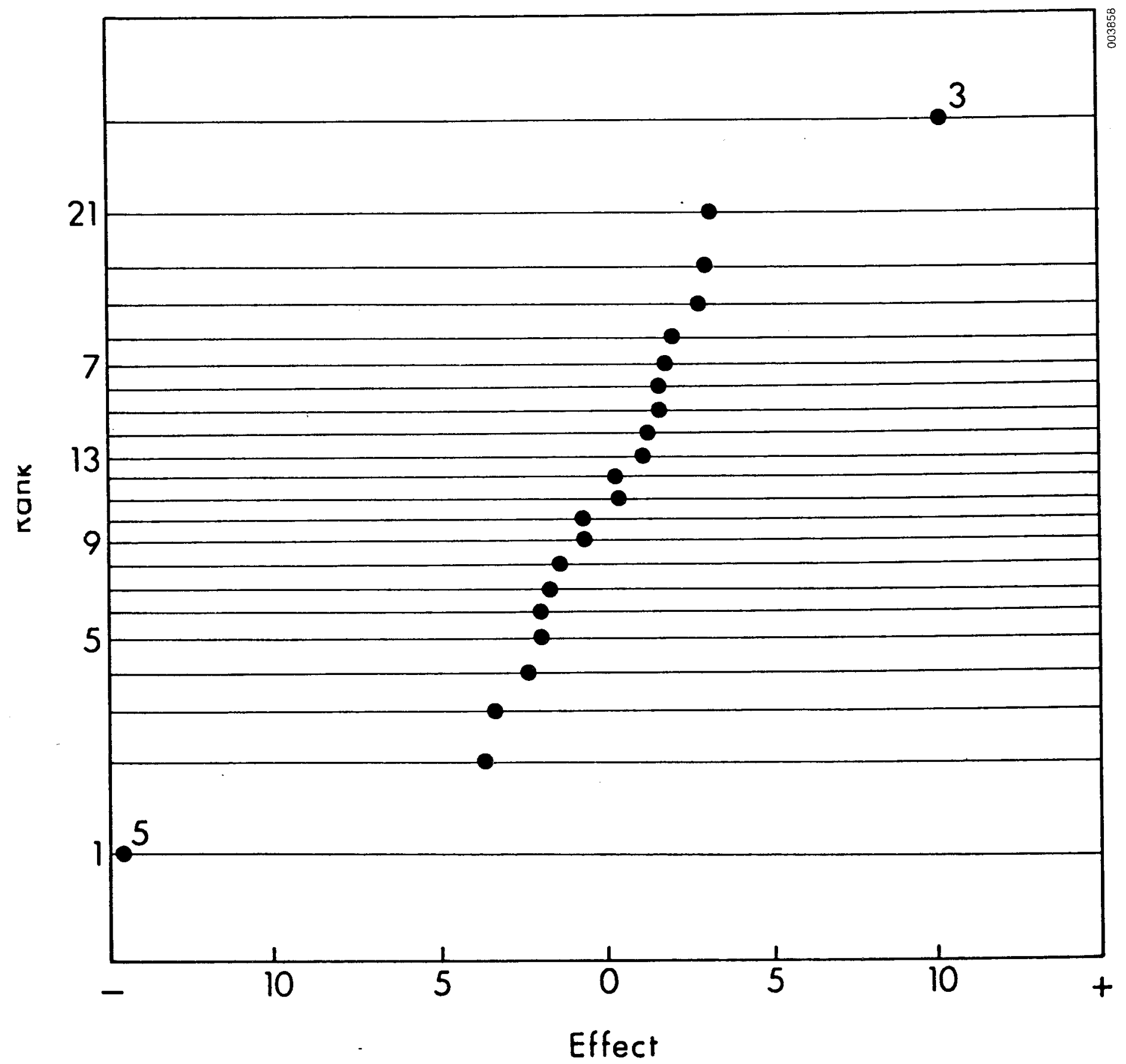

Figure 3-1. Normal plot of factor effects on observed culture temperature. 
by the cultures, as well as other biological parameters, were not so simple to distinguish. Figure 3-2 shows factor effects on culture carbon production $\left(\mathrm{gC} \mathrm{m}^{-2} \mathrm{~d}^{-1}\right)$. No effect, with the possible exception of 1 (depth), lies outside the predictions of probability. The second largest single factor effect was due to salinity (factor 8), but this factor is confounded with block effects, as are the largest two-factor interactions, 16 and 24 . Photosynthetic efficiency effects, calculated on the basis of carbon production, showed a particularly tight linear relationship on a normal plot (Figure 3-3). Not surprisingly, factor 1 and the block effects 8,16 , and 24 were also the most significant.

Although none of the biological effects showed significantly non-normal distributions, it does not necessarily follow that the calculated effects do not represent real responses to the variable factors. The significance of the effects could be better evaluated if the variability of repeated runs under constant conditions were known. In the absence of such data, we took the standard deviation of the observed effects as a maximum estimate of the variability of the repeated runs, and normalized the effects to this standard deviation (Table 3-5). Based on the data in Table 3-5, we have listed in Table 3-6 the most important factors affecting biomass production, lipid production and photosynthetic efficiency.

By far the most significant factor affecting production and photosynthetic efficiency was culture depth. Deeper cultures showed greater production, because self-shading effects were more than offset by higher areal standing crops. Higher areal standing crops might also be achieved by increased culture density, but the latter variable is not always under the control of the culture operator. The second most important factor affecting biomass production and photosynthetic efficiency was $\mathrm{pH}$ ( $\mathrm{CO}_{2}$ supply cut-in); cultures which did not receive $\mathrm{CO}_{2}$ until the pH reached 9 showed less production. Increased dilution caused decreased production, because the standing crop was reduced to too low a level. Increased temperature gave increased production, an expected result if the temperature range of the species is not exceeded.

\subsection{SELECTION OF VARIABLES FOR FURTHER STUDY}

Depth, and thus areal culture density, was the most clearly significant factor in determining production. Since our $9.2 \mathrm{~m}^{2}$ flumes were designed to be operated at a maximum depth of $10 \mathrm{~cm}$, we elected to conduct further experiments at that depth. The $48 \mathrm{~m}^{2}$ flume is the only facility available to us which could be used to study the effect of changes in culture depth at depths much greater than $10 \mathrm{~cm}$. We are skeptical that the use of foils to effect systematic vertical mixing would be very useful in cultures much over $10 \mathrm{~cm}$ deep. In any case we felt that experimentation with culture depths greater than $10 \mathrm{~cm}$ was best postponed for later work with the $48 \mathrm{~m}^{2}$ flume, since conducting such experiments in the 


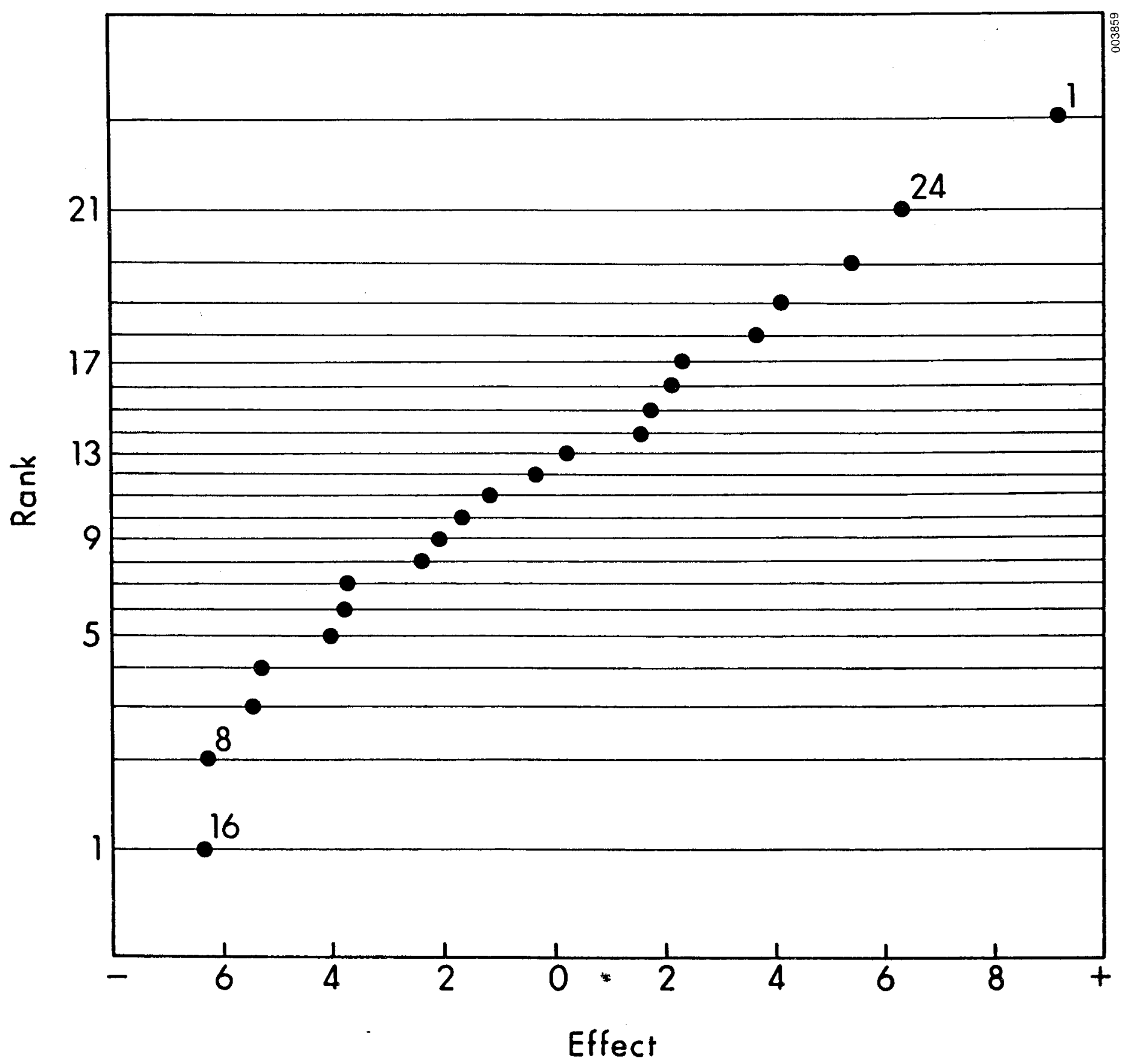

Figure 3-2. Normal plot of factor effects on carbon production. 


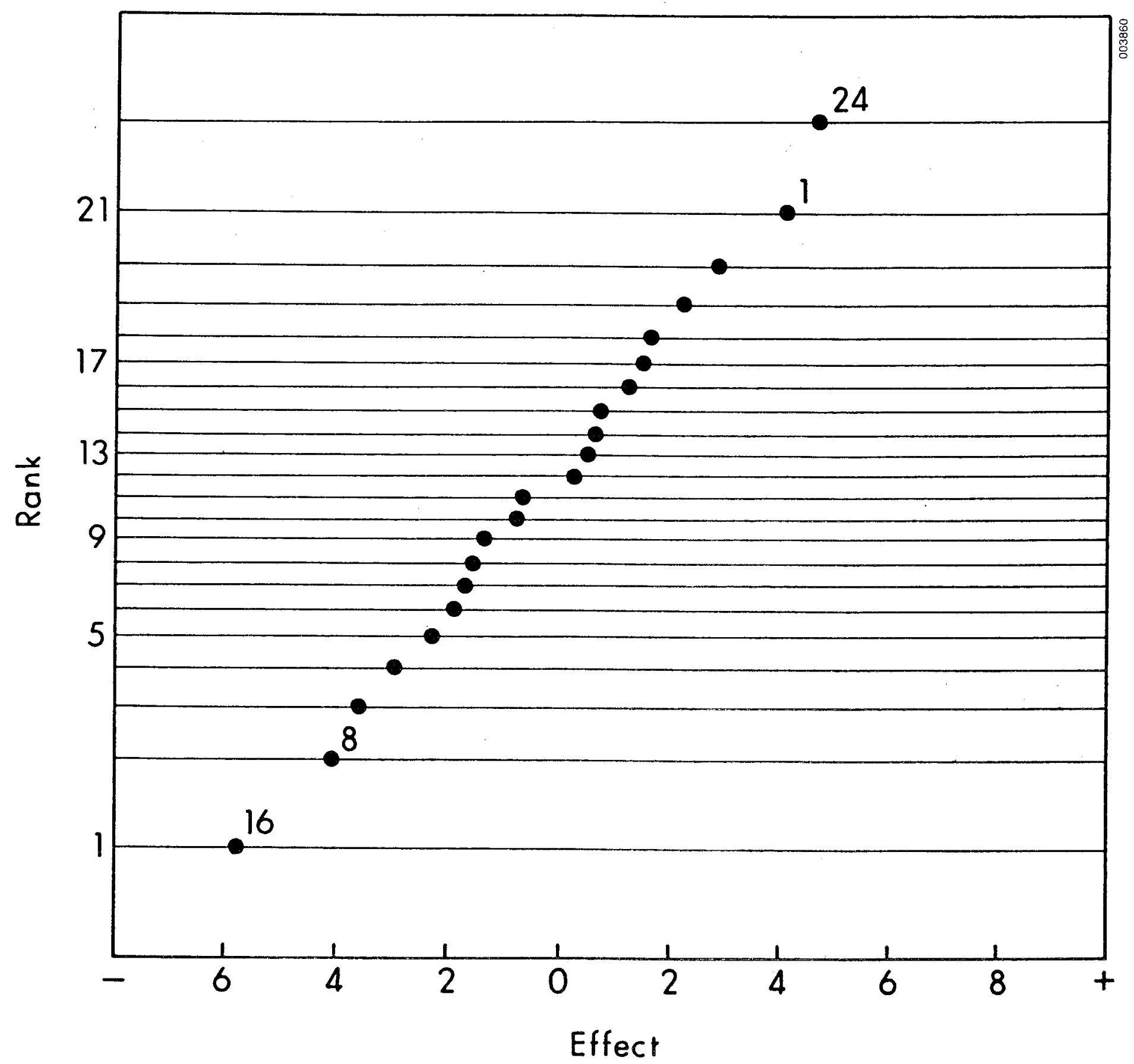

Figure 3-3. Normal plot of factor effects on photosynthetic efficiency. 
Table 3.6 Most important factors affecting production and photosynthetic efficiency.

Response

BIOMASS PRODUCTION

LIPID PRODUCTION

PHOTOSYNTHETIC EFFICIENCY
Factor

Depth

$\mathrm{pH}\left(\mathrm{CO}_{2}\right.$ cut-in)

Dilution Rate

Temperature (chiller cut-in)

Depth

Dilution Rate

$\mathrm{pH}\left(\mathrm{CO}_{2}\right.$ cut-in)

Temperature (chiller cut-in)

Depth

$\mathrm{pH}$

Temperature (chiller cut-in)

Dilution Rate
$+0.76$

Effect (s.d.'s)

$+2.13$

$-1.13$

$-0.80$

$+0.78$

$+1.91$

$-1.14$

$-0.77$

$+2.13$

$-1.28$

$+0.76$

$-0.74$ 
$9.2 \mathrm{~m}^{2}$ flumes would require major modifications to raise the sides.

Previous work $(24,25)$ has made it clear that the ability of P. tricornutum to dominate outdoor mass cultures diminishes rapidly as the temperature is raised from 20 to $25^{\circ} \mathrm{C}$. Our results indicated a positive correlation between production and temperature in the range $15-20^{\circ} \mathrm{C}$, but because of the difficulty in maintaining P. tricornutum cultures at temperatures a few degrees above $20^{\circ} \mathrm{C}$, we felt it was reasonable to establish the operating temperature at $20^{\circ} \mathrm{C}$.

With culture depth and temperature thus established at levels at or very close to optimum values, we concluded that pH and dilution rate were the most important variables for further study. Flow rate had a positive effect on production and efficiency (Table 3-5), and was therefore set at $30 \mathrm{~cm} \mathrm{sec}^{-1}$ for further studies. This flow rate is about the maximum we can achieve in our present flumes. Due to the negative effect of the copper sulfate panels on production and photosynthetic efficiency, we chose not to apply these panels in the optimization experiments. The results in Table 3-5 indicate that ammonium (-sign in factorial) was superior to urea (+ sign in factorial) as a nitrogen source, but it is debatable whether the difference is statistically significant. To be on the safe side, we decided to use NHt in further studies. Production and photosynthetic efficiency were greater at $15 \%$ (- sign in factorial) than at $35 \% / 00$ ( + sign in factoria1). The effect was of debatable statistical significance, but again to be on the safe side we chose to conduct further experiments at $15^{\circ} / 00$.

\subsection{TASK II: YIELD OPTIMIZATION}

Objective: - To determine how much P. tricornutum production can be obtained from a SAMCS

- To determine the sensitivity of the production function to changes in design characteristics

Purpose - To determine whether SAMCS are significantly more productive than conventional algal mass culture systems

Based on the results obtained in Task $I$, we elected to perform a two-way, first-order factorial design experiment to determine the local slope of the response surface, and in particular to determine the equation for the path of steepest ascent to the approximate location of the production peak. Dilution rate and pH were the two parameters to be varied. Our Task I results had indicated that both pH and dilution rate were negatively correlated with production in the pH range 8-9 and the dilution rate range $20-40 \%$. However, a surprising result emerged when we began to explore the response function at pH values less than 8. Although we continued to find a negative correlation between production 
and $\mathrm{pH}$, the correlation between production and dilution rate was now positive. The approximate equation for the path of steepest ascent was

$$
\text { Dilution Rate }=484-58 \mathrm{pH}
$$

The explanation for this relationship is apparent in Figure 3-4. The percentage of inorganic carbon present as $\mathrm{CO}_{2}$ in water dramatically increases as the $\mathrm{pH}$ is lowered below 8 . At pH values between 8 and 9 , almost al1 the inorganic carbon is bicarbonate. Thus varying the $\mathrm{pH}$ between 8 and 9 has relatively little influence on the availability of $\mathrm{CO}_{2}$. The implication of our results is that in order to produce high growth rates in a dense culture of $\underline{P}$. tricornutum, one must not only add supplemental inorganic carbon, but must also insure that more than a small percentage is present as $\mathrm{CO}_{2}$ rather than bicarbonate.

One additional piece of information guided our search for the region of the production peak. We knew from previous work that the maximum growth rate of $\underline{P}$. tricornutum corresponded to almost exactly a tripling of the biomass in one day (33). Since growth at the maximum growth rate implies no light limitation, it is reasonable to conclude that maximum areal production would be achieved if the culture were diluted once each day by less than $67 \%$. Equation 3 implies that the pH corresponding to a dilution rate of $67 \%$ per day would be about 7.2. For our second-order factorial design, we elected to explore the response function in the pH range 7.2 to 8.4 and the dilution rate range $30-60 \%$ per day.

The results of this analysis are shown in Figure 3-5. Production was positively correlated with dilution rate for $30 \% \leq \mu \leq 50 \%$, but production at dilution rates of $50 \%$ and $60 \%$ was essentially the same. The optimum pH was estimated to be $7.0-7.5$, and the optimum dilution rate 50-60\%. The curves drawn in Figure $3-5$ were obtained by expanding the response function (production) in a power series of the form

$$
\begin{aligned}
P\left(\mathrm{gC} \mathrm{m}^{-2} \mathrm{~d}^{-1}\right)= & \mathrm{C}_{\mathrm{o}}+\mathrm{C}_{1} \mu+\mathrm{C}_{2} \mathrm{pH}+\mathrm{C}_{3} \mu^{2}+\mathrm{C}_{4} \mathrm{pH}^{2} \\
& +\mathrm{C}_{5} \mu \mathrm{pH}+\mathrm{C}_{6} \mu^{4}
\end{aligned}
$$

where $\mu$ is dilution rate and the $C_{i}$ are constants. A careful examination of the data suggests that this truncated expansion probably creates one misleading impression. The curves show a positive correlation between $\mathrm{pH}$ and production at the lower end of the pH range. Actually our data show no evidence of such a positive correlation; we susepct that between a pH of 7 and the optimum pH at each $\mu$ there is very little correlation between pH and production. However, forcing the $\mathrm{pH}$ to a value less than the optimal value would waste $\mathrm{CO}_{2}$. Therefore it seems reasonable to operate the flume at the optimum $\mathrm{pH}$ implied by the curves in Figure 3-5, and to keep the dilution rate in the range $50-60 \%$. 


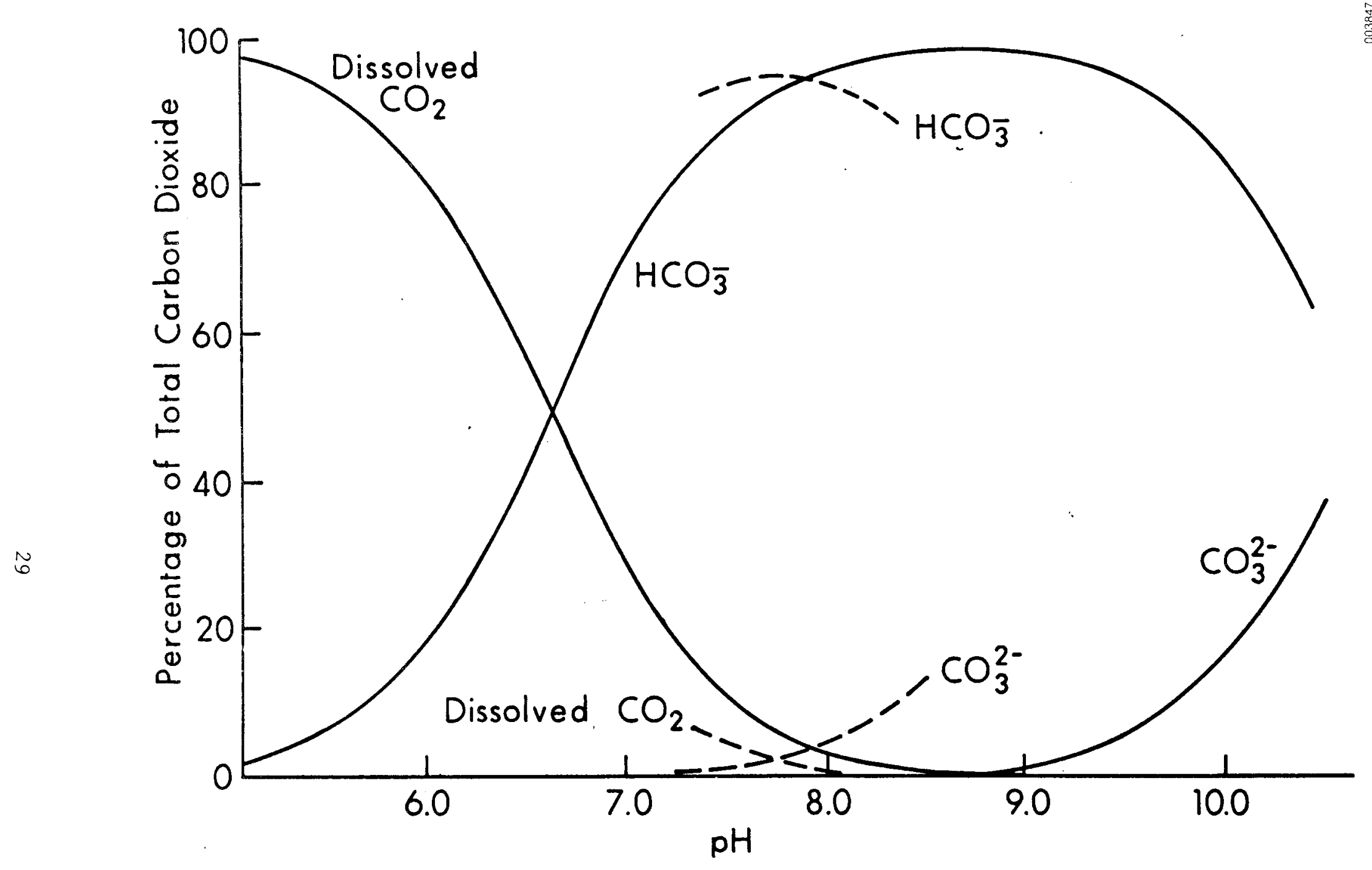

Figure 3-4. Percentages of dissolved carbon dioxide, bicarbonate ion and carbonate ion as a function of $\mathrm{pH}$ at $0^{\circ} \mathrm{C}$. Continuous line, distilled water; broken line sea water. 


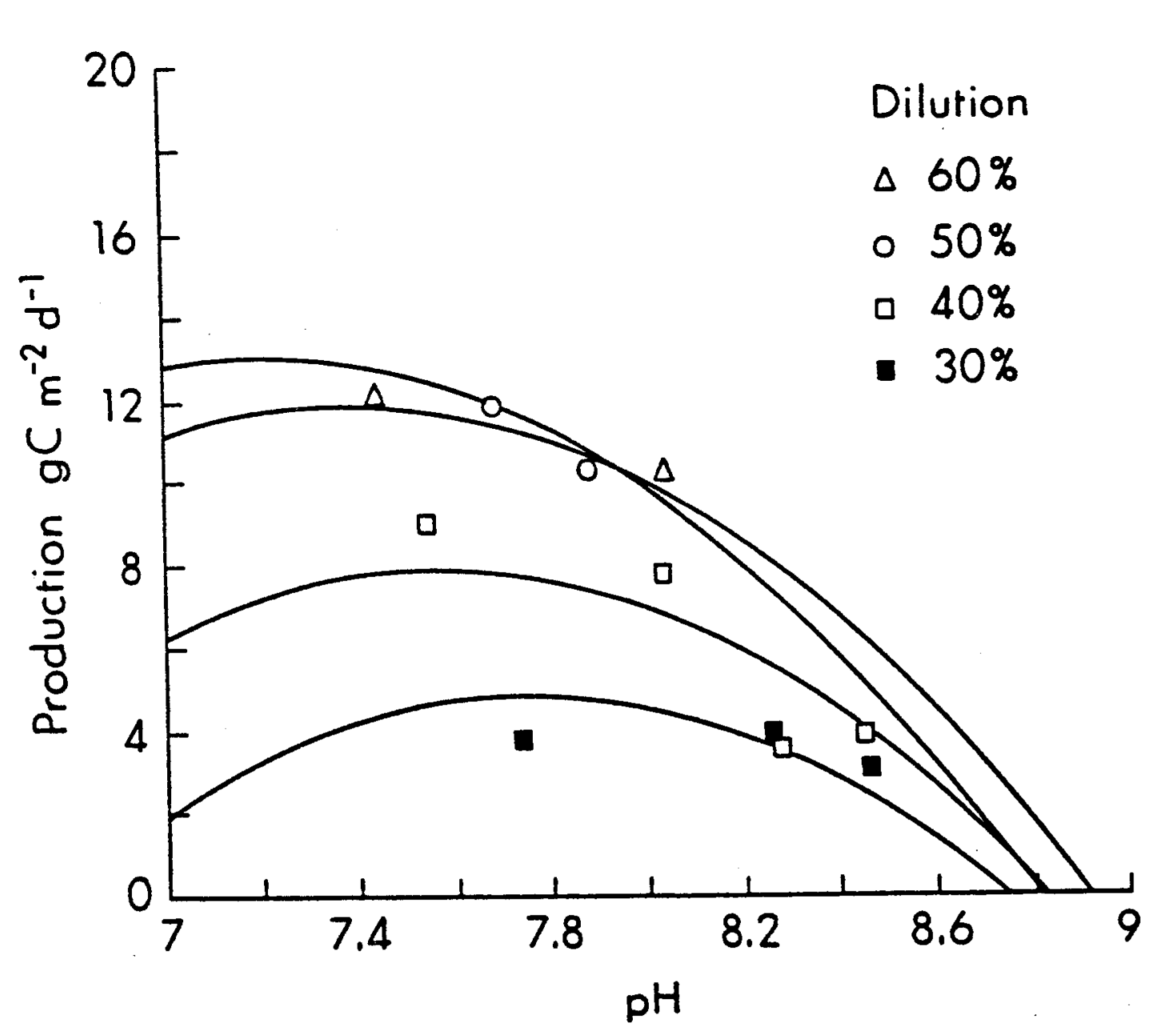

Figure 3-5. Production of carbon in experimental flumes as a function of $\mathrm{pH}$ and dilution rate. Curved lines are equation 4. 
The least squares fit of Equation 4 to our data indicates that maximum production of about $26 \mathrm{~g}$ dry wt $\mathrm{m}^{-2} \mathrm{~d}^{-1}$ is achieved at a pH of 7.25 and at $\mu=57.6 \%$. Production is predicted to drop by about $30 \%$ if $\mu$ is reduced to $40 \%$ per day, and by roughly another $30 \%$ if $\mu$ is reduced to $30 \%$ per day. Production is fairly sensitive to $\mathrm{pH}$ for $\mathrm{pH}$ values above the optimum. For example, at $\mu=40 \%$, production drops by about a factor of two as $\mathrm{pH}$ is increased from 7.6 to 8.4 (Figure 3-5). However, at $\mathrm{pH}$ values below or near the optimum $\mathrm{pH}$, production is rather insensitive to changes in $\mathrm{pH}$. This fact is apparent from the observation that production at $\mu=30 \%$ was a 1 most independent of $\mathrm{pH}$ for $\mathrm{pH}$ values between 7.7 and 8.5 .

Probably the most complete and up-to-date summaries of algal mass culture production figures are those of Goldman (34) and Aaronson and Dubinsky (35). The highest yields that have been achieved with . tricornutum are $9.8 \mathrm{~g}$ dry wt $\mathrm{m}^{-2} \mathrm{~d}^{-1}$ by Ansell et a1. (36) during May-August in England and 12.4-13.3 g dry wt $\mathrm{m}^{-2} \mathrm{~d}^{-1}$ by Goldman et a1. (37). The production actually achieved in our flumes was $24 \mathrm{~g}$ dry wt $\mathrm{m}^{-2} \mathrm{~d}^{-1}$, and our analysis of the production function indicates that about $26 \mathrm{~g}$ dry wt $\mathrm{m}^{-2} \mathrm{~d}^{-1}$ could be achieved under optimal conditions. Thus we have been able to roughly double the best previous production figures from a P. tricornutum culture. This result is consistent with our earlier estimate (38), which indicated that use of foils in a flume culture system would increase production 2.2-2.4 fold.

The highest production that has been achieved on an extended basis in a culture growing solely on inorganic nutrients is $23 \mathrm{~g}$ dry wt m-2 $\mathrm{d}^{-1}$ (34). That production figure was achieved with a freshwater culture of Scenedesmus over a 62-day period On a short-term basis production as high as $35 \mathrm{~g}$ dry wt m-2 $\mathrm{d}^{-1}$ has been achieved in cultures growing on wastewater or inorganic nutrients (34). My opinion is that one of the critical factors limiting production of $P$. tricornutum is the fact that the temperature of the culture must not rise much above $20^{\circ} \mathrm{C}$. It is reasonable to assume that algae adapted to growth at higher temperatures would be able to fix carbon more rapidly at those higher temperatures. For example, Goldman et al. (37) report optimum production of about $13 \mathrm{~g}$ dry wt $\mathrm{m}^{-2} \mathrm{~d}^{-1}$ in cultures grown at Woods Hole (latitude $41^{\circ} 52^{\prime} \mathrm{N}$ ) and about $24 \mathrm{~g}$ dry wt $\mathrm{m}^{-2} \mathrm{~d}-1$ at Fort Pierce (latitude $27^{\circ} 28^{\prime} \mathrm{N}$ ). The culture systems in both cases consisted of 2000 l open-air ponds. The production results from both experiments pertain to results obtained during the May-October period. Although differences in irradiance undoubtedly account for some of the difference in the production figures, I suspect that part of the difference reflects the higher temperatures at the Fort Pierce site. It is noteworthy for example that at Woods Hole $\underline{P}$. tricornutum dominated the cultures in May and June, and was subsequently replaced by Amphiphora sp. and later Amphora sp.. However, at Fort Pierce 
Nitzchia closterium dominated the cultures over the entire study period. Evidently the ponds in the Fort Pierce study were

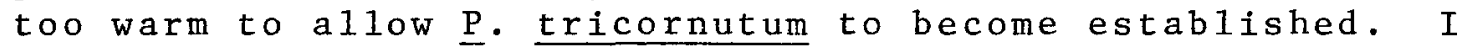
suspect that production in our flumes can be significantly enhanced when we switch from p. tricornutum to some of the mesophilic species we are currently studying. The mesophilic species grow well in the temperature range $30-35^{\circ} \mathrm{C}$, whereas P. tricornutum must be maintained at $20-25^{\circ} \mathrm{C}$.

Anse11 et al. (36) reported photosynthetic efficiencies averaging $3.7 \%$ over a two-week period in their $\underline{\text { P. tricornutum cultures. }}$ Under optimal conditions, our photosynthetic efficiencies averaged about 5.6\% (Figure 3-6), about a 50\% improvement over the best results achieved by Anseli et al. (36). The curves drawn in Figure 3-6 were obtained from an expansion similar to equation 4 , and predict a maximum in photosynthetic efficiency at a pH of 7.5 and a dilution rate of $53 \%$ per day, values practically indentical to those obtained from the analysis of the production data in Figure 3-5.

\subsection{TASK III: ANALYSIS, MODELING, \& LABORATORY SUPPORT STUDIES}

objectives: - To perform functional analysis to provide a common framework for the comparison of biological responses to physical treatments

- To execute laboratory experiments which answer specific questions regarding algal reponse to culture conditions

- To attempt to find strains of Phaeodactylum which are superior in terms of temperature tolerance and light utilization

Purpose: - To provide additional information on variables which cannot be adequately studied in the mass cultures

The specific subtasks performed under this task involved a) the development of a theoretical model to predict the potential increase in production which could be achieved utilizing the flashing light effect, b) the development of a cheap and effective means of harvesting the cells, c) an attempt to find strains of $\underline{P}$. tricornutum better suited to mass culture than the strain we obtained from W. Thomas at Scripps, and d) the performance of various other laboratory experiments and analyses to elucidate physical, chemical, and biological processes in the mass culture and to test innovative culture manipulation strategies prior to their application in mass culture. We report the results obtained under each of these categories in the following discussion.

\subsection{THEORETICAL ANALYSIS OF POTENTIAL ADVANTAGE OF FLASHING IIGHT EFFECT FOR MASS CULTURE WORK}

This analysis is based on the experimental and theoretical studies 


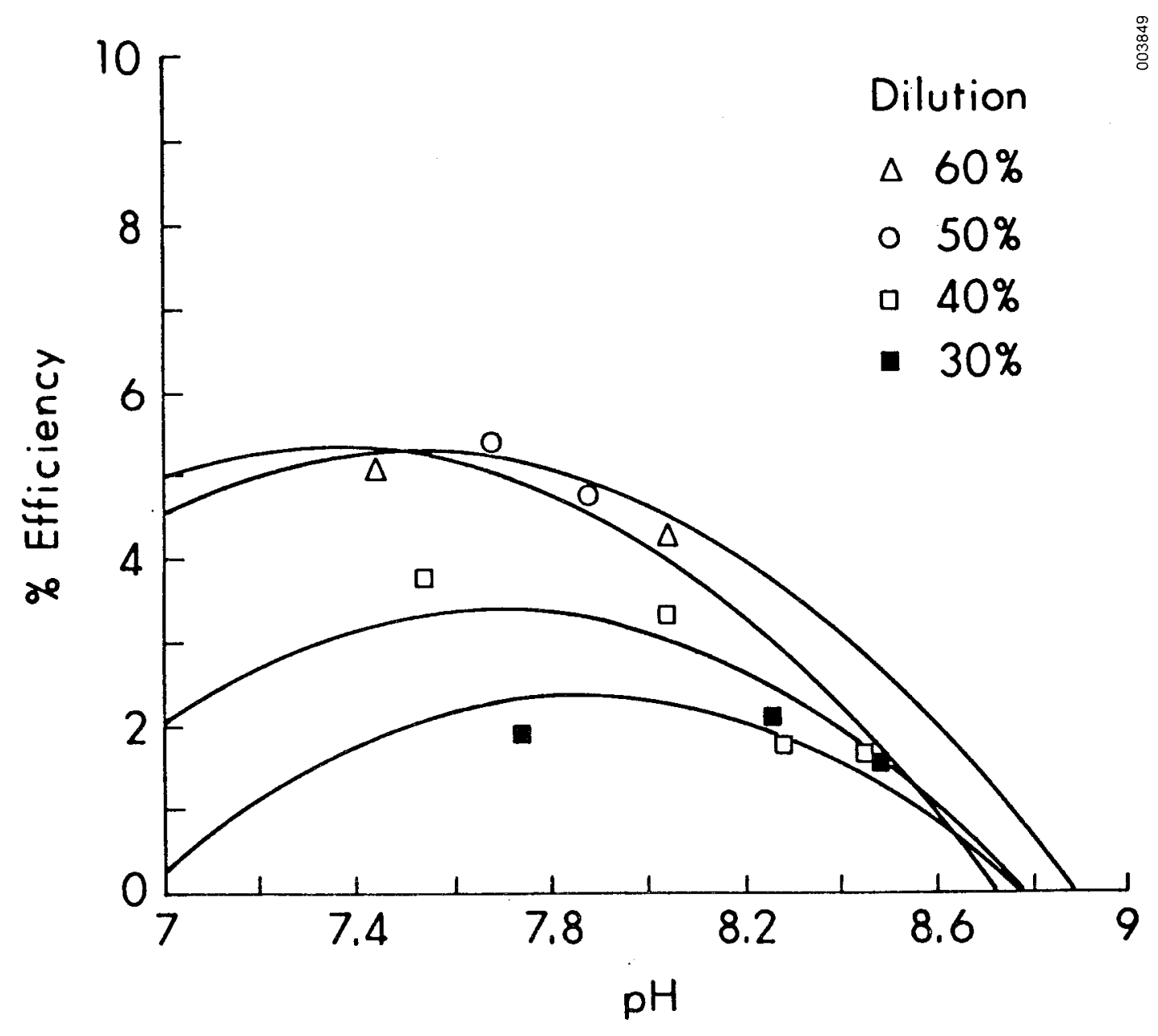

Figure 3-6. Photosynthetic efficiency in experimental flumes as a function of $\mathrm{pH}$ and dilution rate. Curved lines are expansion similar to equation 4 . 
of light-limited algal growth presented by Bannister (39). Under continuous light conditions we assume that algal growth can be described by the equations

$$
\begin{aligned}
\mu & =\left(\mu_{\mathrm{m}}+\mathrm{L}^{\prime}\right) \xi /\left(\xi_{\mathrm{g}}^{\mathrm{n}}+\xi^{\mathrm{n}}\right)^{1 / \mathrm{n}}-\mathrm{L}^{\prime} \\
& =\left\{\xi \emptyset_{\mathrm{m}} \mathrm{K} /\left[(\theta \mathrm{K})^{\mathrm{m}}+\xi^{\mathrm{m}}\right]^{1 / \mathrm{m}}-\mathrm{a}\right\} /(1+\mathrm{b}) \\
\xi & =\mathrm{K}_{c^{I}} \\
\mathrm{~L}^{\prime} & =\mathrm{a} /(1+\mathrm{b})
\end{aligned}
$$

where $\mu$ is the growth rate $\left(t^{-1} e^{-1}\right)$, I is the light irradiance (quanta.area-1.time ${ }^{-1}$ ), $\xi$ is the specific absorbed irradiance (quanta absorbed $\cdot m g$ ch1 $\underline{a}^{-1} \cdot t_{i m e^{-1}}$ ), $\theta$ is the $c: c h 1$ a ratio, and $\mu_{\mathrm{m}}, \mathrm{K}_{\mathrm{c}}, \xi_{\mathrm{g}}, \emptyset_{\mathrm{m}}, \mathrm{K}, \mathrm{a}, \mathrm{b}, \mathrm{n}$ and $\mathrm{m}$ are constants. The values assigned to these constants are listed in Table 3-7.

To apply the model to growth under light:dark cycle conditions, one assumes that the relationship between $\theta$ and $\mu$ under 1 ightlimited conditions is independent of photoperiod. Bannister (39) cites evidence to support this assumption. Although equation 5 applies only to growth under continuous light conditions, equation 6 can be modified to describe growth under light:dark cycle conditions by simply multiplying $\emptyset_{\mathrm{m}}$ by $f$, the photoperiod expressed as a fraction of a day. For example, if the photoperiod is 16 hours, then $\mathrm{f}=2 / 3$. For our model we assumed a photoperiod of $12 \mathrm{~h}$ and therefore took $\mathrm{f}=0.5$.

Equation 5 can be inverted to solve for $\xi$ as a function of $\mu$. The result is

$$
\xi=\xi_{g}\left(\mu+L^{\prime}\right) /\left[\left(\mu_{m}+L^{\prime}\right)^{n}-\left(\mu+L^{\prime}\right)^{n}\right]^{1 / n}
$$

The right-hand side of equation 9 can be substituted for $\xi$ in equation 6. The resulting equation contains only two variables, $\mu$ and $\theta$, and is the equation which determines the unique relationship between $\theta$ and $\mu$. The resultant equation is

$\theta=\left\{\xi_{g}\left(\mu+L^{\prime}\right) /\left[\left(\mu_{m}+L^{\prime}\right)^{n}-\left(\mu+L^{\prime}\right)^{n}\right]^{1 / n}\right\}\left\{\phi_{m}^{m} /[\mu(1+b)+a]^{m}-K^{-m}\right\}^{/ m}$

Now consider the case of growth under light:dark cycle conditions in a column of water in which the cells are slowly mixed. In that case it is reasonable to assume that the growth rate of the cells at each depth in the water column is described by equation 6, with $\phi_{\mathrm{m}}$ replaced by $\mathrm{f} \phi_{\mathrm{m}}$ and with $\theta$ determined by equation 10 . However, we know that $\theta$ cannot change on the same time scale (seconds or at most minutes) as the process of vertical mixing. It is therefore reasonable to assume that $\theta$ is the same for all the cells 
Table 3-7. Parameter values used to characterize the Bannister (39) model.

$\begin{array}{ll}\mu_{\mathrm{m}}\left(\mathrm{d}^{-1}\right) & 2.5 \\ \mathrm{~K}_{\mathrm{c}}\left(\mathrm{m}^{2} \cdot \mathrm{mg} \mathrm{ch} 1 \underline{\mathrm{a}}^{-1}\right) & 0.0105 \\ \xi_{\mathrm{g}}\left(\text { Einst absorbed } \cdot \mathrm{mg} \mathrm{ch} 1 \mathrm{a}^{-1} \mathrm{~d}^{-1}\right) & 0.0462 \\ \emptyset_{\mathrm{m}}(\mathrm{gC} \cdot \text { Einst absorbed } & -1 \\ \mathrm{~K}\left(\text { Einst absorbed } \cdot \mathrm{gC}^{-1} \cdot \mathrm{d}^{-1}\right) & 0.7 \\ \mathrm{a}\left(\mathrm{d}^{-1}\right) & 5.7 \\ \mathrm{~b} \text { (dimensionless) } & 0.072 \\ \mathrm{n} \text { (dimensionless) } & 0.117 \\ \mathrm{~m} \text { (dimensionless) } & 2.0\end{array}$


in the culture. This value of $\theta$ is estimated by substituting $\bar{\mu}$, the average growth rate of all the cells in the culture, for $\mu$ in equation 10 . We must therefore satisfy the following condition:

$$
\bar{\mu}=\frac{1}{D(1+b)} \int_{0}^{D}\left\{\xi f \phi_{m} K /\left[(\theta K)^{m}+\xi^{m}\right]^{1 / m}-a\right\} d z
$$

where $\theta$ is obtained from the right-hand side of equation 10 by substituting $\bar{\mu}$ for $\mu$, and

$$
\xi=\xi_{0} e^{-K_{c} \cdot Z \cdot c h 1} \underline{a}
$$

In equation $12 \xi$ is the specific absorbed irradiance at the surface of the culture, and we have assumed that all the attenuation of light in the culture is due to absorption by algal pigments. Obviously equation 11 is a transcendental equation in $\bar{\mu}$, but since we know that $0 \leq \bar{\mu} \leq \mu$, it is easy to solve the equation by the bisection metho $\bar{d}(4 \overline{0})$. m' In general the integration over depth can be handled numerically, and closed expressions are available for certain values of $\mathrm{m}$.

Now the whole idea of utilizing the flashing light effect is to prevent the cells from responding to the light level at each depth, but instead to respond only to the average irradiance in the culture. In that case $\mu$ is obtained from the equation

$$
\mu=\left\{\bar{\xi} \mp \emptyset_{\mathrm{m}} \mathrm{K} /\left[(\theta \mathrm{K})^{\mathrm{m}}+\bar{\xi}^{\mathrm{m}}\right]^{1 / \mathrm{m}}-\mathrm{a}\right\} /(1+\mathrm{b})
$$

where $\theta$ is obtained from equation 10 and $\bar{\xi}$ is the average specific absorbed irradiance over the depth of the culture. Hence

$$
\bar{\xi}=\xi_{0}\left(1-e^{-K_{c}} \cdot \mathrm{D} \cdot \mathrm{Ch} 1 \underline{\mathrm{a}}\right) /\left(\mathrm{K}_{\mathrm{c}} \cdot \mathrm{D} \cdot \mathrm{Ch} 1 \underline{\mathrm{a}}\right)
$$

Equation 13 is still a transcendental equation in $\mu$, but again can be solved easily by the bisection method. Thus a comparison of the effect of flashing light on production in an algal culture can be made by comparing $\mu$ calculated from Equation 13 with $\bar{\mu}$ calculated from equation 11 . The ratio $\mu / \bar{\mu}$ will depend both on the incident irradiance and on the areal chl a density (ch1 a.D). In Hawail the ayerage irradiance in the visibie region is about 100 Einst $\mathrm{m}^{-2} \mathrm{~d}^{-1}$ (i.e. in a twelve hour photoperiod each $\mathrm{m}^{2}$ receives 50 Einst). At production rates of $10 \mathrm{gC} \mathrm{m}^{-2} \mathrm{~d}^{-1}$, our flume contains in the range of $0.5-1.0 \mathrm{~g}$ chl a $\mathrm{m}^{-2}$. Figure $3-7$ shows the ratio $\mu / \bar{\mu}$ at three areal chl a densities and irradiances up to 100 Einst $\mathrm{m}^{-2} \mathrm{~d}^{-1}$.

Several features about the plots are of interest. First, at very low incident irradiances there is no flashing light effect, because production is almost a linear function of $\xi$ at low values of $\xi$. Second, at very low chl a densities there is no 


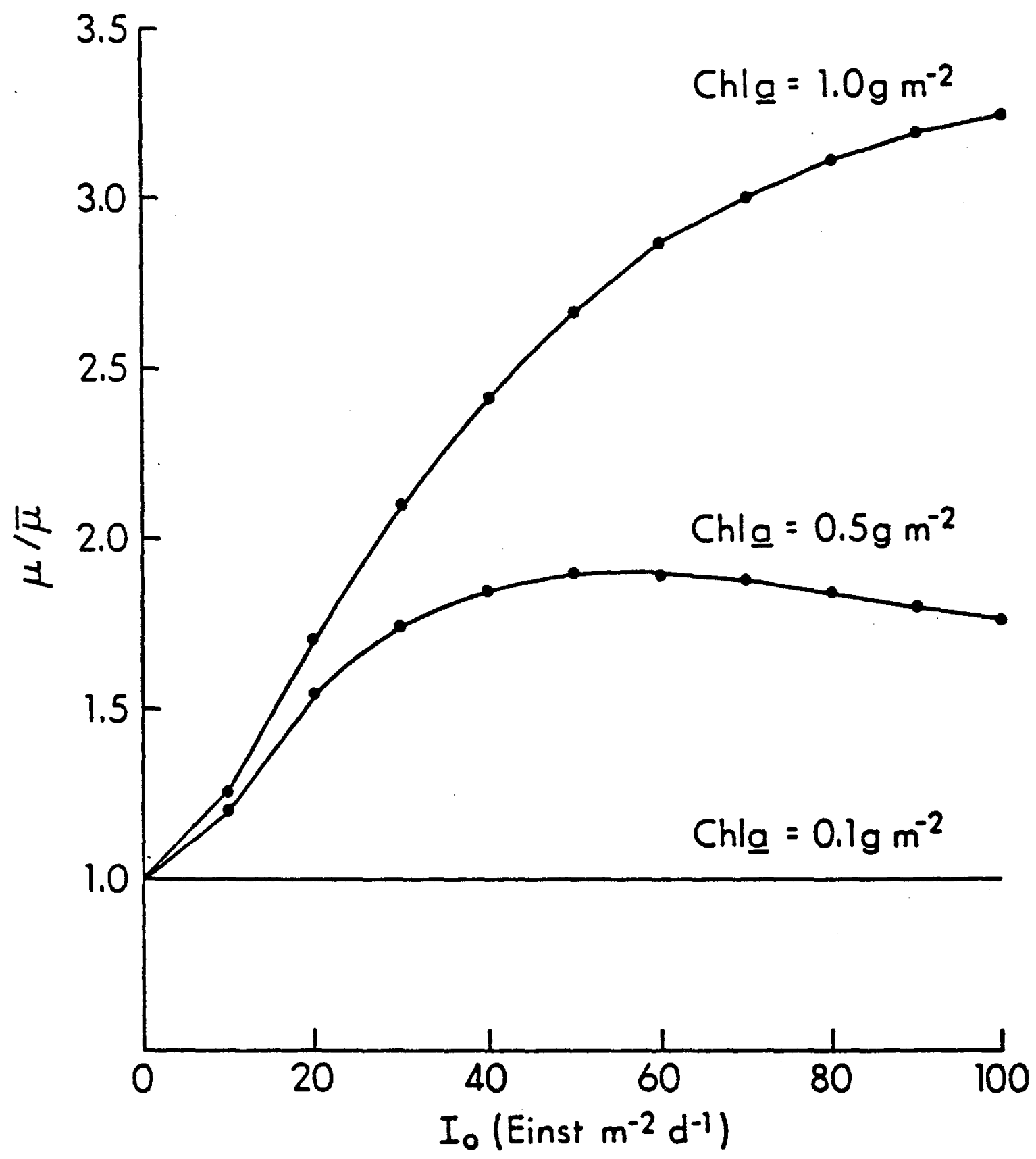

Figure 3-7. Ratio of growth rate under ideal flashing light regime to growth rate in absence of flashing light effect as a function of incident irradiance and areal ch1 a concentration using equations 11 and 12 . 
flashing light effect, because $\xi \simeq \bar{\xi}_{0}$. Third, at a ch1 a density of $0.5 \mathrm{~g} \mathrm{~m} \mathrm{~m}^{-2}$, there is a peak in the ratio $\mu / \bar{\mu}$ at $I_{0} \simeq 50$ Einst $\mathrm{m}^{-2} \mathrm{~d}^{-1}$. This peak occurs because as $I_{0}$ increases to $\bar{h}$ igh values $\bar{\xi}$ approaches an irradiance which almost saturates photosynthesis. In this case $\xi_{0}>\xi$, but if both $\xi_{0}$ and $\bar{\xi}$ are out on the asymptote of the $\mu$ versus $\xi$ curve, the cells will respond to $\xi$ in essentially the same way that they respond to $\xi_{0}$. At $\operatorname{chl} \underline{a}=1.0 \mathrm{~g} \mathrm{~m}^{-2}$, the peak in the $\mu / \bar{\mu}$ ratio is evidently reached at $I_{0}>100$ Einst $\mathrm{m}^{-2} \mathrm{~d}^{-1}$. Finally, at chl a densities between 0.5 and $1.0 \mathrm{~g} \mathrm{~m}^{-2}$, the model predicts that at $I_{0} \simeq 100$ Einst $m^{-2} d^{-1}$, the flashing light effect can be expected to enhance production by somewhere between 80 and

$225 \%$. This theoretical prediction is consistent with our experimental results, which show enhancements between 50 and $100 \%$ in production and photosynthetic efficiency.

\subsection{ALGAL HARVESTING STRATEGIES}

We had hoped to be able to study the surface charge (Zeta potential) of the cells as a function of growth conditions, and to relate this surface charge to the tendency of the cells to flocculate and sink. Unfortunately we were not able to learn anything useful from these studies. The surface charge on the cells is apparently so low that there is virtually no movement in an electric field over the time period needed to perform the experiments. A technician on another project used the Zeta meter to study the surface charge on clay particles, and reported that the Zeta meter was working fine. Therefore the problem was not with the Zeta meter. All I can say at this point is that the Zeta potential on $\underline{P}$. tricornutum cells is less than about $10 \mathrm{mV}$.

We were however successful in identifying a mechanism for harvesting the cells cheaply and efficiently. We had earlier explored the possibility of harvesting foam from the flume as a means of removing the cells in a concentrated form. However, because the optimum dilution rate is apparent 1 y $50-60 \%$ per day, we needed a harvesting mechanism which could deal with large volumes of water and remove the cells with virtually $100 \%$ efficiency. The foam harvester would be suitable if we wanted the water in the flume to have a very long residence time. However, that mode of operation would lead to very low production, probab1y because of the accumulation of waste products in the water.

I have earlier reported that simply raising the $\mathrm{pH}$ of the water through addition of $\mathrm{NaOH}$ causes a flocculation and rapid settling of the cells. We have since quantified this phenomenon. The cells flocculate rapidly when $\mathrm{NaOH}$ is added at a concentration of about $5 \mathrm{mM}$. The sinking rate of the cells under these conditions is about three meters per hour. Let us assume for the 
moment that we harvest half the volume of the flume each day, and that the flume is $10 \mathrm{~cm}$ deep. If we are willing to allow 12 hours for settling the cells, the surface area required for the settling operation would be $(0.1 \mathrm{~m})(0.5) /$ $[(3 \mathrm{~m})(12)]=0.14 \%$ of the area of the flume itself. It is likely that much of the $\mathrm{NaOH}$ added to the water could be recovered as precipitated $\mathrm{Na}_{2} \mathrm{CO}_{3}$ along with the cells, and recycled many times.

\subsection{SUITABILITY OF OTHER STRAINS OF PHAEODACTYLUM}

We obtained five strains of $\underline{\text { P }}$ tricornutum from the University of Texas culture collection, and examined the growth rate of these species as a function of temperature at 20,25 and $28^{\circ} \mathrm{C}$ The results are shown in Table 3.8. The principal discovery was that al1 of the University of Texas (UTEX). strains were able to grow at $28^{\circ} \mathrm{C}$, whereas the Thomas strain is dead at $28^{\circ} \mathrm{C}$. UTEX strains 640 and 642 showed substantially better growth at $28^{\circ} \mathrm{C}$ than did the other UTEX strains. The growth rates reported for the UTEX strains are in the cell concentration range

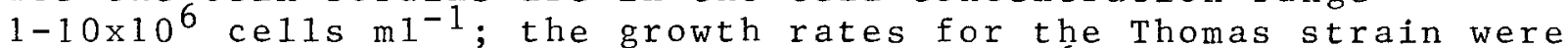
obtained at cel1 concentrations of $10-30 \times 10^{6}$ ce $11 \mathrm{~s} \mathrm{~m} 1^{-1}$. Since growth rates decline as cell concentrations increase, the difference between the Thomas strain growth rates and the UTEX strains growth rates at $20^{\circ} \mathrm{C}$ and $25^{\circ} \mathrm{C}$ are probably not significant. Since the temperature in our uncooled flumes can easily rise to $32-33^{\circ} \mathrm{C}$ during the day, it is doubtful if even the UTEX strains would be suitable for mass culture in Hawaii. UTEX strains 2089 and 2090 had lower 1ipid contents than the Thomas strain. The general conclusion is that there are strains of p. tricornutum more tolerant to high temperatures than the Thomas strain, but it is debatable whether these strains would do well in outdoor culture in Hawaii, and it also appears questionable whether lipid production would be increased by switching to one of the UTEX strains.

\subsection{LABORATORY SUPPORT STUDIES}

An experiment was conducted to determine the reproducability of lipid analyses on samples taken from the experimental flumes. on eight consecutive days between $6 / 21 / 83$ and $6 / 28 / 83$ samples of the P. tricornutum culture were taken from experimental flume number four. The cells were analyzed for lipid content, and for the percentage of the lipid accounted for by neutral and polar lipids. The results are presented in Table 3-9. The results were highly reproducible.

During the course of the factorial experiment, we twice ran all four flumes under identical conditions to determine the reproducability of the results. Table 3-10 summarizes the results of these two experiments. The results indicated that the 
Table 3-8. Growth rate and lipid content of six strains of $\underline{P}$. tricornutum. Growth rates are in units of $\mathrm{d}^{-1}$.

$\begin{array}{lccc}\text { Strain } & 20^{\circ} \mathrm{C} & 25^{\circ} \mathrm{C} & 28^{\circ} \mathrm{C} \\ \text { Thomas } & 0.31 & 0.14 & - \\ \text { UTEX 640 } & \text { no data } & 0.20 & 0.23 \\ \text { UTEX } 642 & 0.35 & 0.18 & 0.17 \\ \text { UTEX 646 } & 0.45 & 0.20 & 0.11 \\ \text { UTEX 2089 } & 0.42 & 0.10 & 0.12 \\ \text { UTEX 2090 } & 0.44 & 0.20 & 0.13\end{array}$

\section{Lipid Content \\ (\% dry weight)}

Thomas at $20.5^{\circ} \mathrm{C}$

$21 \%$ ( $16 \%$ neutra1)

UTEX 2089 at $20^{\circ} \mathrm{C}$

$10 \%(23 \%$ neutral)

UTEX 2090 at $20^{\circ} \mathrm{C}$

$15 \%$ (23\% neutral) 
Table 3-9. Results of lipid analyses on flume $\underline{P} \cdot$ tricornutum culture on eight consecutive days.

$\begin{array}{lccc} & \text { Mean } & \text { Standard Deviation } & \text { Range } \\ \begin{array}{l}\text { Lipids as } \% \\ \text { of dry weight }\end{array} & 24.6 & 1.0 & 23.2-26.4 \\ \begin{array}{l}\text { Neutral lipids as } \\ \% \text { of total lipids }\end{array} & 22.5 & 3.0 & 18.4-26.4 \\ \begin{array}{l}\text { Polar lipids as } \\ \% \text { of total lipids }\end{array} & 77.5 & 3.0 & 73.6-81.6\end{array}$


Table 3-10. Summary of flume experiments to determine reproducability of production results.

\begin{tabular}{|c|c|c|c|}
\hline Time Period & $\mathrm{pH}$ & Dilution Rate & Photosynthetic Efficiency \\
\hline $7 / 8-7 / 19$ & 8.3 & $30 \%$ & $1.90 \pm 0.40$ \\
\hline $8 / 25-8 / 28$ & 7.7 & $50 \%$ & $5.62 \pm 0.39$ \\
\hline
\end{tabular}


standard deviation on the photosynthetic efficiency on a given flume was about $0.4 \%$. We considered this result to be acceptable for our purposes.

At the January meeting in San Diego, Larry Raymond suggested to me that addition of selenium or nickel to the culture medium might result in an increase in the lipid content of P. tricornutum. To test this hypothesis cultures of $\bar{P}$. tricornutum were grown in FCRG (Scripps Food Chain Research Group) medium, and exposed to concentrations of selenium and nickel from two to 1000 times normal seawater concentrations. Two $500 \mathrm{~m} 1$ replicate batch cultures were innoculated at each of the three metal levels; two control cultures were grown in FCRG without additional $\mathrm{Ni}$ or Se. Nickel was added as nickel chloride; selenium was added as selenious acid. Cultures were also innoculated with two $\mu$ Curies of C-14 bicarbonate. Cultures were grown in continuous light and allowed to reach constant density $\left(3.5-4.0 \times 10^{6}\right.$ cells $\left.\mathrm{ml}^{-1}\right)$ before harvesting.

Subsamples from each culture were filtered onto glass fiber (GF/C) filters for triplicate particulate carbon and nitrogen analysis, and for triplicate analysis of the percent of the C-14 activity in the lipid fraction. The results are shown in Table 3-11. Data from replicate batch cultures have been combined, since there were no significant differences between replicate cultures. The percent of carbon allocated to lipids ranged from 29.3 to $32.4 \%$. An analysis of variance showed no significant differences between treatments. Carbon:nitrogen ratios ranged between 5.9 and 6.6 by weight. Again there was no significant difference between treatments. Growth rates also appeared unchanged, since final cell concentrations were approximately equal after equal time periods. We concluded that adding selenium and/or nickel to the cultures was not worth pursuing further. 
Table 3-11. Results of adding selenium and nickel to cultures of $\underline{P}$. tricornutum.

$\underline{\text { Treatment }} \quad \begin{gathered}\text { Selenium added } \\ \left(\mu \mathrm{g} \ell^{-1}\right)\end{gathered}$

\section{Control}

Low metals

Medium metals

High metals

0

0.4

9

400
Nickel added

$\left(\mu \mathrm{g} e^{-1}\right)$

\% lipid

C:N (by weight)

0

2.0

20

140
32.4

29.8

29.3

30.9
6.63

6.34

5.87

6.17 


\subsection{TaSk IV: PERFORMANCE SENSITIVITY ANALYSIS}

objective:

Purpose:
- To prepare an evaluation of system inputs which quantifies operational parameters and identifies opportunities for improvement

- To provide the data required to guide this emerging technology toward effective application

The following is an analysis of construction and annual maintenance costs of the experimental Algal Raceway Facility at the University of Hawaii Manoa. This section of the report will also compare the costs of a research facility to a production facility. After evaluating the data it became apparent that there are several areas in which price reductions could be significant. They are Personnel, Electricity, and Construction materials used in the raceway proper. i.e. Concrete versus Fiberglass flumes in a production system.

In evaluating the construction costs of the current experimental facility we analyzed the materials used in the four small flumes, which have a total area of 448 square feet. By adding up the entire construction material costs and dividing by the area we obtained a price per square foot. Basically the calculation went as follows:

$\begin{array}{lr}\text { Fiberglass } & \$ 2,000.00 \\ \text { Plumbing } & \$ 2,800.00 \\ \text { Foundation (raceway support system) } & \$ 2,700.00 \\ \text { Cooling } & \$ 6,800.00 \\ \text { Total } & \$ 14,300.00 \\ \text { Divide by } 448 \mathrm{sq} . \mathrm{ft} . & \$ 31.92 / \mathrm{sq} . \mathrm{ft} .\end{array}$

Using this figure we were able to extrapolate the price in construction materials for moving from an experimental to a production system. The following four system options and their costs were calculated for an acre facility with $60 \%$ of the area under water $(26,136 \mathrm{sq} . \mathrm{ft}$.$) :$
A) Fiberglass flumes with cooling $\$ 805,000.00$ System
B) Concrete Flumes with Cooling $\$ 633,000.00$
C) Concrete Flumes without Cooling $\$ 238,000.00$
D) Fiberglass Flumes without Cooling $\$ 410,000.00$

It should be noted that the concrete used in this estimate is a standard 4 inches thick; reduction of this thickness would decrease the cost considerably. Also this does not include land preparation. 
Maintenance costs for the experimental facility were broken down into five categories

1) Office Expenses

2) Laboratory Expenses

3) Construction/System Maintenance

4) Electricity (with cooling) (without)

5) Personne1

Totals with cooling without cooling
$\$ 6,100.00$

$\$ 8,300.00$

$\$ 7,200.00$

$\$ 19,200.00$

$\$ 6,000.00$

$\$ 50,600.00$

$\$ 91,400.00$

$\$ 78,200.00$

The above categories include the following items: Office Expenses: mileage, photocopying, phone, and trave1; Lab expenses: nutrients, chemicals, lab supplies and computer maintenance; Construction/ System Maintenance: includes routine systematic maintenance and alterations of the system for experimental purposes; Electricity: includes routine facility power, and cooling costs for the raceways and culture rooms; Personnel: Includes 2 full time lab technicians at the university facility for analyzing results, 1 full time $1 \mathrm{ab}$ technician at the raceway for monitoring production, and 1 $3 / 4$ time maintenance person for system maintenance and experimental improvements.

In evaluating the transition from an experimental to production facility the following items were cited as possible areas for cost reduction:

Cooling: the cooling costs appear prohibitive in both the construction and maintenance areas

Personnel: the costs of personnel would be greatly reduced in a production facility due to a reduction in scientific analysis and research consideration. i.e. once there is a transition to production, questions on production variables will be settled. 
REFERENCES

1. Burk, D., Cornfield, J., and Schwartz, M. 1951. The efficient transformation of light into chemical energy in photosynthesis. Sci. Month1y, 73: 213-223.

2. Clendenning, K.A. and Ehrmantraut, H.C. 1950. Photosynthesis and Hill reactions by whole Chlorella cells in continuous and flashing 1ight. Arch. Biochem., 29: 387-403.

3. Emerson, R. and Arnold, W. 1932a. A separation of the reactions in photosynthesis by means of intermittent light. J. Gen. Physio1., $15: 391-420$.

4. Emerson, R. and Arnold, W. 1932b. The photochemical reaction in photosynthesis. Jour. Gen. Physiol.,16: 191-205.

5. Rieke, F.F. and Gaffron, H. 1943. Flash saturation and reaction periods in photosynthesis. J. Phys. Chem.,47: 299-308.

6. Tamiya, H. and Chiba, Y. 1949. Analysis of photosynthetic mechanism by the method of intermittent illumination. Stud. Tokugawa Inst., 6: $1-129$.

7. Weller, S. and Franck, J. 1941. Photosynthesis in flashing light. J. Phys. Chem., 45: 1359-1373.

8. Falkowski, P.G. and Wirick, C.D. 1981. A simulation model of the effects of vertical mixing on primary productivity. Mar. Biol., 65: 69-75.

9. Kok, B. 1953. Experiments on photosynthesis by Chlorella in flashing light, In: Algal Culture from Laboratory to Pilot Plant. Burlew, J.S. (ed). (Carnegie Inst. of Washington, Washington, DC), Pub1. No. 600 , pp. 63-75.

10. Kok, B. 1956. Photosynthesis in flashing light. Biochim. Biophys. Acta, 21: 245-258.

11. Mark1, H. 1980. Mode11ing of alga1 production systems. In: Shelef, G. and Soeder, C.J. (eds). Algae Biomass. Elsevier-North Holland. Amsterdam. pp. 361-383.

12. Marra, J. 1978a. Effect of short-term variations in 1ight intensity on photosynthesis of a marine phytoplankter: a laboratory simultation study. Mar. Biol. 46:191-201.

13. Marra, J. 1978b. Phytoplankton photosynthetic response to vertical movement in a mixed layer. Mar. Biol., 46: 203-208.

14. Phillips, J.N. and Myers, J. 1954. Growth rate of Chlorella in flashing light. Plant Physiol., 29: 152-161. 
15. Powe11, C.K., Chaddock, J.B., and Dixon, J.R. 1965. The motion of algae in turbulent flow. Biotech Bioeng. 7: 295-308.

16. Sager, J.C., and Giger, W. 1980. Re-evaluation of published data on the relative photosynthetic efficiency of intermittent and continuous light. Agricul. Meteor., 22: 289-302.

17. Fredrickson, A.G., and Tsuchiya, H.M. 1969. Utilization of the effects of intermittant illumination on photosynthetic microorganisms. In: Prediction and Measurement of Photosynthetic Productivity, Proceedings of the IBP/PP Technical Meeting, Trebon, September,1969 (Centre for Agricultura1 Publications \& Document, Wagenegen, Netherlands).pp. 519-541.

18. Seibert, M., and Lavorel, J. 1982. Oxygen-evolution and patterns from oxygen-evolving photosystem II particles. In: Solar Energy Research Institute Biomass Program Principal Investigators' Review Meeting. Agenda and Abstracts. Washington, D.C., June 23-25, 1982. p. 17.

19. Miller, R.L., Fredrickson, A.G., Brown, A.H., and Tsuchiya, H.M. 1964. Hydromechanical method to increase efficiency of algal photosynthesis. Ind. Engng. Chem. Proces Des. Deve1., 3: 134-143.

20. Davis, E.A., Dedrick, J., French, C.S., Milner, H.W., Myers, J., Smith, J.H.C., and Spoehr, H.A. 1953. Laboratory experiments on Chlorella culture at the Carnegie Institution of Washington department of plant biology. In: Algal Culture from Laboratory to Pilot Plant. Burlew, J.s., (ed). Carnegie Inst. of Washington, Washington, D.C. pp. 105-153.

21. Howe11, J.A., Fredrickson, A.G., and Tsuchiya, H.M. 1966. Optimal and dynamic characteristics of a continuous photosynthetic algal gas exchanger. Chem. Engng. Prog. Symp. Ser. 62(68): 56-58.

22. Oswald, W.J., Golueke, C.G., and Horning, D.0. 1965. Closed ecological systems. Proc. Am. Soc. Civ. Engrs. (Sanitary Engineering),91(SA4): 23-46.

23. Shelef, G., Sabanas, M., and Oswald, W.H. 1968. An improved algatron reactor for photosynthetic life support systems. Proc. 14th Ann. Techn. Meeting Inst. Envir. Sci.

24. Goldman, J.C., and Mann, R. 1980. Temperature-influenced variations in speciation and chemical composition of marine phytoplankton in outdoor mass cultures. J. Exp. Mar. Biol. Ecol., 46: 29-39.

25. Goldman, J.C., and Ryther, J.H. 1976. Temperature-influenced species competition in mass cultures of marine phytoplankton. Biotec. and Bioeng., 18: $1125-1144$.

26. Ketchum, B.H., Lillick, L., and Redfield, A.C. 1949. The optimum growth and optimum yields of unicellular algae in mass culture. J. Cell. and Comp. Physiol., 33: 267-280.

27. Mann, J.E., and Myers, J. 1968. Photosynthetic enhancement in the diatom Phaeodactylum tricornutum. Plant Physio1., 43: 1991-1995. 
28. McLachlan, J. 1964. Some considerations of the growth of marine algae in artificial media. Can. J. Microbiol.,10: 769-782.

29. Raymond, L.P. 1978. Initial Investigations of a shallow-layer alga1 production system. Hawaii Natural Energy Institute Tech. Rept. No. 7. $38 \mathrm{pp}$.

30. Goldman, J.C., and Stanley, H.I. 1974. Relative growth of different species of marine algae in wastewater-seawater mixtures. Mar. Biol., 28: 17-25.

31. Sharp, J.H. 1974. Improved analysis for "particulate" organic carbon and nitrogen from seawater. Limno1. Oceanogr.,19: 984-989.

32. Strickland, J.D.H. 1958. Solar radiation penetrating the ocean. A review of requirements, data and methods of measurement, with particular reference to photosynthetic productivity. J. Fish. Res. Bd. Canada, 15: 543-493.

33. Terry, K.L., Hirata, J., and Laws, E.A. 1983. Light-1imited growth of two strains of the marine diatom Phaeodactylum tricornutum Bohlin: Chemical Composition, Carbon Partitioning and the Diel Periodicity of Physiologica1 Processes. J. Exp. Mar. Bio1. Ecol., 68: 209-227.

34. Goldman, J.C. 1979. Outdoor algal mass cultures - I. Applications. Water Res., 13: 1-19.

35. Aaronson, S., and Dubinsky, Z. 1982. Mass Production of microalgae. Experientia, 38: 36-40.

36. Anse11, A.D., Raymont, J.E.G., Lander, K.F., Crowley, E., and Shackley, P. 1963. Studies on the mass culture of Phaeodactylum. II. The growth of Phaeodactylum and other species in outdoor tanks. Limnol. Oceanogr., 8: 184-206.

37. Goldman, J.C., Ryther, J.H., and Williams, L.D. 1975. Mass production of marine algae in outdoor cultures. Nature, 254: 594-595.

38. Laws, E.A., Terry, K.L., Wickman, J., and Chalup, M.S. 1983. Results from a simple algal production system designed to utilize the flashing light effect. Biotech. Bioeng., in press.

39. Bannister, T.T. 1979. Quantitative description of steady state, nutrientsaturated algal growth, including adaptation. Limnol. Oceanogr., 24: 76-96.

40. Hornbeck, R.W. 1975. Numerical Methods. Quantum Publishers. New York. $310 \mathrm{pp}$. 


\begin{tabular}{|c|c|c|}
\hline $\begin{array}{l}\text { Document Control } \\
\text { Page }\end{array}$ & \begin{tabular}{|l|l|} 
1. SERI Report No. & 2. NTIS Accession No. \\
SERI/STR-231-2206 & \\
\end{tabular} & 3. Recipient's Accession No. \\
\hline \multirow{2}{*}{\multicolumn{2}{|c|}{$\begin{array}{l}\text { 4. Title and Subtitle } \\
\text { Research, Development, and Demonstration of Algal } \\
\text { Production Raceway (APR) Systems for the Production } \\
\text { of Hydrocarbon Resources }\end{array}$}} & $\begin{array}{l}\text { 5. Publication Date } \\
\text { February } 1984\end{array}$ \\
\hline & & 6. \\
\hline \multicolumn{2}{|l|}{$\begin{array}{l}\text { 7. Author(s) } \\
\text { Edward A. Laws }\end{array}$} & 8. Performing Organization Rept. No. \\
\hline \multirow{2}{*}{\multicolumn{2}{|c|}{$\begin{array}{l}\text { 9. Performing Organization Name and Address } \\
\text { University of Hawai } \\
\text { Oceanography Department and Hawai I Institute } \\
\text { of Marine Biology } \\
\text { 1000 Pope Road } \\
\text { Honolulu, Hawai } 96822\end{array}$}} & $\begin{array}{l}\text { 10. Project/Task/Work Unit No. } \\
1358.10\end{array}$ \\
\hline & & $\begin{array}{l}\text { 11. Contract (C) or Grant (G) No. } \\
\text { (C) XE-0-9013-01 } \\
\text { (G) }\end{array}$ \\
\hline \multirow{2}{*}{\multicolumn{2}{|c|}{$\begin{array}{l}\text { 12. Sponsoring Organization Name and Address } \\
\text { Solar Energy Research Insti tute } \\
1617 \text { Cole Boulevard } \\
\text { Golden, Colorado } 80401\end{array}$}} & $\begin{array}{l}\text { 13. Type of Report \& Period Covered } \\
\text { Technical Report }\end{array}$ \\
\hline & & 14. \\
\hline \multicolumn{3}{|c|}{$\begin{array}{l}\text { 15. Supplementary Notes } \\
\text { Technical Monitor: Robins McIntosh }\end{array}$} \\
\hline \multicolumn{3}{|c|}{ 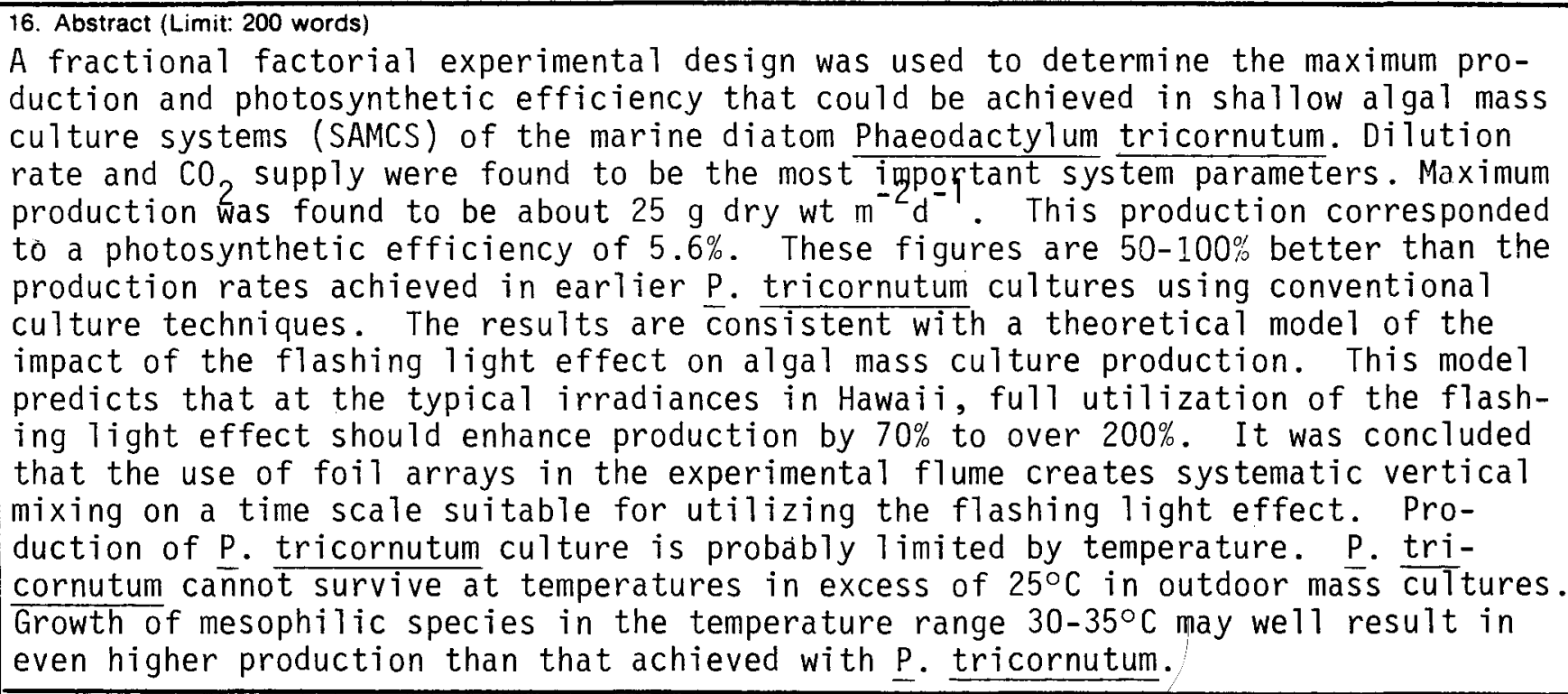 } \\
\hline \multirow{2}{*}{\multicolumn{3}{|c|}{$\begin{array}{l}\text { 17. Document Analysis } \\
\text { a. Descriptors } \mathrm{A} 7 \mathrm{ga}\end{array}$}} \\
\hline & & \\
\hline \multicolumn{3}{|l|}{ c. UC Categories } \\
\hline \multicolumn{3}{|l|}{$61 a$} \\
\hline \multirow{2}{*}{\multicolumn{2}{|c|}{$\begin{array}{l}\text { 18. Availability Statement } \\
\text { National Technical Information Service } \\
\text { U.S. Department of Commerce } \\
5285 \text { Port Roya } 1 \text { Road } \\
\text { Springfield, Virginia } 22161\end{array}$}} & $\begin{array}{r}\text { 19. No. of Pages } \\
59\end{array}$ \\
\hline & & A04 \\
\hline
\end{tabular}

